\title{
Regulatory Failure, Regulatory Reform, and Structural Change in the Electrical Power Industry
}

Utility rate litigation has become sport, a vent for passions. Each contest satiates for the moment, then fuels the appetite for further fight. We shrink from the thought of the season ending. . . . I am hard pressed to imagine a more inefficient, haphazard approach to utility rate making than our state has witnessed in recent years. ... Our Public Service Commission presents an innovative and promising . . . way out and we deliver a stiff left to the jaw.

Justice Robertson, Mississippi Supreme Court, State of Mississippi et al. v. Mississippi Public Service

Commission and Mississippi Power Company, January 4, 1989

In the past decade the U.S. economy has gone through a virtual revolution in economic deregulation. Complete or partial deregulation of prices and market entry has increased the role of market forces in allocating resources in industries as diverse as airlines, telecommunications, natural gas production and transmission, and financial services. But the electric power industry, at least on the surface, has been largely unaffected. The industry is still subject to extensive price and entry regulation by state and federal regulatory agencies and has not yet experienced the dramatic structural changes that have followed deregulation elsewhere. Nevertheless, several significant changes are taking

I have benefited from comments by Douglas Bohi, Frank Gollop, and Peter Reiss. Financial support from the MIT Center for Energy Policy Research, the MIT Department of Economics Energy Research Fund, and the Olin Foundation is gratefully acknowledged. This paper was written while I was a visiting scholar at Harvard Law School. 
place in the structure and regulation of the electric power industry. Most important is the increasing role of competing suppliers of wholesale power to utilities for resale, the resulting gradual deintegration of the industry, and the regulatory changes promoting competition for future supplies of generating capacity acquired by utilities for resale to residential, commercial, and industrial customers.

During the 1950s and most of the 1960s the electric power industry attracted little attention from public policy makers. It experienced high productivity growth, falling nominal and real prices, excellent financial performance, and little regulatory or political controversy. Utilities rarely had to file for rate increases, there were few formal hearings, and "voluntary" rate decreases were the norm. ${ }^{1}$ The system worked smoothly. While numerous academic and government studies identified imperfections in the industry's performance, proposals for reform focused on relatively modest adjustments of regulatory policies and the desirability of more coordination among utilities, many of which were deemed too small to exploit available economies of scale. Major structural and regulatory reforms were not high on political agendas.

Economic conditions changed in the late 1960s and early 1970s. Productivity growth disappeared, and key costs, particularly for fuel and interest, rose. With prices fixed by regulation, profitability fell: a growing number of utilities filed for rate increases. Various interest groups organized to resist the increases in the formal hearing process and to exert pressure for changes in regulatory procedures and rate structures. After 1973 utilities requested much larger rate increases because of large, unanticipated, and mostly uncontrollable increases in costs. These requests further intensified political resistance to rate increases and created pressures for regulatory changes that would deal with the problems caused by rapidly rising electricity costs. Regulatory resistance to price increases caused utilities' financial performance to decline precipitously. By the late 1970s the system that had appeared to

1. Paul L. Joskow, "Inflation and Environmental Concern: Structural Change in the Process of Public Utility Price Regulation," Journal of Law and Economics, vol. 17 (October 1974), pp. 291-327; and Joskow, "Pricing Decisions of Regulated Firms: A Behavioral Approach," Bell Journal of Economics and Management Science, vol. 4 (Spring 1973), pp.119-40. 
work so smoothly for so long was near collapse, plagued by controversies that had not been associated with the industry since the early 1930s. ${ }^{2}$

The seeds of current developments can be found primarily in the responses of regulatory commissions, legislatures, and utilities during the 1970s and 1980s to changes in the economic environment and in the regulatory institutions that determined how cost fluctuations were supposed to be translated into retail electricity prices. Probably the most important long-term responses to the perceived problems that emerged in the 1970s and early 1980s are associated with the growing importance of wholesale power markets, especially the development of a competitive independent generating sector made up of power-supply entities that sell power to distribution utilities without being subject to traditional price and market entry regulations.

Increased opportunities for wholesale trade between distribution utilities that traditionally generated their own power emerged in the late 1970 s and early 1980 s as a consequence of the unanticipated price differences between coal, oil, and natural gas, the fuels used to generate most electricity, combined with excess generating capacity in most regions of the country. Federal and state regulations issued after 1980 in accordance with the Public Utility Regulatory Policy Act of 1978 (PURPA) encouraged unintegrated nonutility generators (NUGs) to enter the market. The reactions of the traditional regulatory structure to the economic changes, the potential opportunities to rely more on a competitive independent generating sector, and the political forces unleashed both by the performance of the traditional system when faced with economic shocks and by the 1978 act increased the political demand for alternative regulatory and structural arrangements to govern the

2. Controversies over the structure and regulation of electric utilities, especially holding companies, in the Great Depression led to two important pieces of legislation. The first, the Federal Power Act of 1935, substantially increased the federal role in regulating wholesale transactions between utilities and mergers between utilities, developing a uniform system of accounts, replacing fair value rate bases with original cost rate bases, and instituting data collection and reporting requirements for all electric utilities. The second, the Public Utility Holding Company Act of 1935 (PUHCA), led to a complete reorganization of the complex holding companies that had emerged during the 1920s and 1930s. Most of the reorganizations required under this act were completed by the mid1950s. Public utility holding companies continue to be subject to regulation under the act by the Securities and Exchange Commission. 
acquisition and operation of new generating capacity. As a result, the United States is now seeing major changes in the ways electric utility generation capacity is procured, in transmission arrangements, and in federal and state rate regulation to accommodate and encourage these changes. These developments will likely increase the importance of sales by independent competing suppliers of wholesale electricity generation service, unencumbered by traditional price regulation, to regulated, partially integrated distribution utilities.

This paper discusses the nature, causes, and likely consequences of these changes. After examining the structure and regulation of the electric power industry as it had evolved by the early 1970 s, I focus on the changes that have occurred in the past decade, particularly the developments in wholesale power markets generally and the growth of an unintegrated independent generating sector in particular. This leads to a discussion of the economic, regulatory, and political forces that have led to these changes. The rest of the paper evaluates the public policies that have stimulated the rapid development of an independent generating sector, increased purchases from independent suppliers, and the growth and importance of competitive wholesale power markets.

\section{The Structure and Regulation of the Industry}

It is impossible to understand the nature and consequences of the changes taking place in the electric utility industry today without a clear understanding of the traditional structure of the industry and the nature of state and federal regulation.

\section{Industry Structure}

Residential, commercial, and industrial customers (referred to collectively in what follows as retail customers) spent over $\$ 150$ billion on electricity in $1987 .{ }^{3}$ Some 3,000 entities distribute electricity to more

3. Residential customers account for about 40 percent of retail revenues, commercial customers for 30 percent, and industrial customers for 27 percent. The category of "other," 3 percent of revenues, includes street lighting, public authorities, railroads, and so forth. For 1987 spending see Edison Electric Institute, Statistical Yearbook of the Electric Utility Industry, 1987 (Washington, 1988), table 56. 
than 100 million retail customers. However, between 75 and 80 percent of the electricity supplied is provided by about 100 independent, private investor-owned utilities (IOUs) ${ }^{4}$ The rest is generated or distributed by 3,000 publicly or cooperatively owned entities that vary widely in size, structure, and form of ownership. ${ }^{5}$

Since the focus of this paper is investor-owned utilities, I will limit the discussion to their structure and regulation. Despite variations in size, IOUs share many common structural and regulatory characteristics (figure 1). The typical utility has traditionally been vertically integrated, generating electricity and transmitting and distributing it to retail customers. As distributors, IOUs typically have either a de jure or de facto exclusive franchise to provide service to the retail customers within their territories. In return, the rates they charge retail customers are subject to regulation by state regulatory commissions. ${ }^{6}$ These utilities also take on an obligation to provide reliable service at regulated rates to all retail customers located within their territories. What economists think of as competition has been relatively unimportant in determining retail electricity rates for at least the past fifty years; multiple franchises authorized to serve the same geographical area are extremely rare. ${ }^{7}$

Historically, IOUs owned all the generation, transmission, and distribution capacity required to serve their retail customers. But as the

4. There are technically more than 200 investor-owned utilities; Electrical World, "Introduction," in Directory of Electric Utilities, 96th ed. (McGraw-Hill, 1988). However, after consolidating utilities that are wholly owned subsidiaries of holding companies and jointly owned wholesale power facilities, and ignoring very small unintegrated distribution companies, the number of independent IOUs is much reduced.

5. These entities include federal power marketing agencies such as TVA and Bonneville, municipal utilities, cooperative distribution entities, and cooperative generation and transmission entities established to facilitate and subsidize rural electrification. They also include various public utility districts and authorities established by the states. Many of the public and cooperative distribution systems rely on the federal power marketing agencies, IOUs, and state or cooperative generation and transmission organizations for all or part of their generation requirements, reselling the power to retail customers.

6. The Federal Power Act of 1935 and the Public Utility Holding Company Act of $\mathbf{1 9 3 5}$ limit federal rate regulation to wholesale transactions between unaffiliated utilities (as defined by the act) and between corporate subsidiaries of interstate holding companies.

7. Walter J. Primeaux, Jr., "The Decline in Electric Utility Competition," Land Economics, vol. 51 (May 1975), pp. 144-48; and Primeaux, Direct Electric Utility Competion: The Natural Monopoly Myth (Praeger, 1986). While in many states electric utility franchises are technically nonexclusive, economic and regulatory barriers to the creation of directly competing distribution systems give most incumbents a de facto 
Figure 1. The Traditional Structure of Investor-Owned Utilities

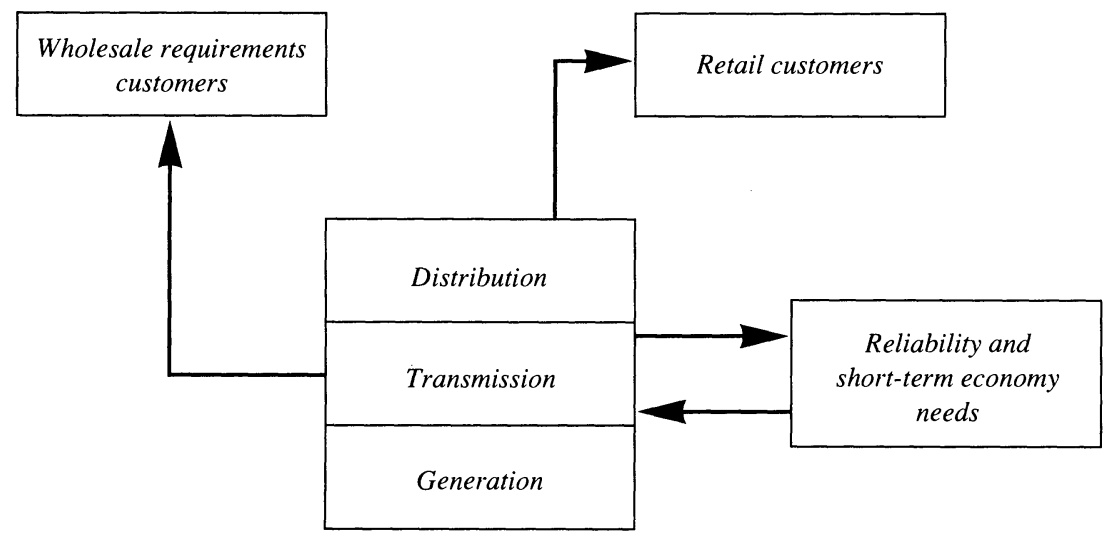

average size of generating facilities grew in the late 1960s and early 1970s, many utilities found that they were too small to exploit economically state-of-the-art, central-station facilities on their own, and joint ownership of generating capacity became common. Developments in transmission and coordination technology have also led to increased interconnection between independent IOUs, joint planning and operation of facilities owned and operated by several proximate utilities, and, especially in the East, formal power-pooling arrangements to enhance reliability and to exploit generating and transmission capacity economically. $^{8}$

IOUs also make a variety of wholesale transactions, defined as sales by one utility to another for resale to retail customers. Since the passage of the Federal Power Act in 1935, wholesale transactions have been regulated by the Federal Energy Regulatory Commission (FERC, formerly the Federal Power Commission). These transactions fall into two broad categories.

exclusive franchise. Franchise exclusivity means that a retail customer at a given location must either purchase electricity from the local utility or generate electricity himself. In a few areas utilities do compete on the fringes of their established service areas or to extend service to industrial facilities at remote sites, but such competition is rare. State regulatory restrictions on price discrimination limit even further the effects of any such competition on prices.

8. Office of Electric Power Regulation, Power Pooling in the United States, FERC0049 (Federal Energy Regulatory Commission, December 1981). 
The first encompasses so-called coordination transactions, a term that emerged to encompass the short-term purchases and sales of electricity engaged in by interconnected integrated utilities to make possible the economical use of generating plants owned by proximate utilities and to ensure reliability. ${ }^{9}$ That is, utilities traditionally owned sufficient generating capacity to meet their loads, and relied on shortterm coordination transactions to ensure economical and reliable joint operation of these facilities. This category of wholesale transaction has expanded in recent years to encompass virtually all voluntary bilateral wholesale contracts that do not involve an open-ended obligation by the seller to provide for the requirements of the purchasing utility. These transactions involve not only the short-term exchanges of energy and capacity, including power-pooling arrangements, but also longer-term purchase and sale contracts. ${ }^{10} \mathrm{By}$ and large IOUs have not built standalone generation and transmission facilities in anticipation of making coordination contracts with other investor-owned utilities. Rather, coordination transactions are generally associated with surplus generating capacity not currently needed by an integrated distribution utility or public utility holding company to provide service to its requirements customers.

The second broad category of wholesale transaction is called a requirements transaction, a sale by an integrated IOU to an unintegrated or partially integrated distribution company that does not own enough generation and transmission capacity to supply its retail customers. Most of these unintegrated (full requirements customers) or partially integrated (partial requirements customers) purchasers are municipal or cooperative distribution utilities operating within the control area of an

9. Office of Economic Policy, Regulating Independent Power Producers: A Policy Analysis (Federal Energy Regulatory Commission, October 13, 1987), pp. 4-5; Wilbur C. Earley, "FERC Regulation of Bulk Power Coordination Transactions,' Working Paper (Federal Energy Regulatory Commission, July 1984); and Federal Energy Regulatory Commission, Notice of Inquiry Re Regulation of Electricity Sales-for-Resale and Transmission Service, 31 FERC 61,376 (1985). "Coordination transaction," the term FERC uses, made some sense when most transactions between integrated utilities were shortterm economy or reliability transactions, but it now makes less sense. Calling them "voluntary contract transactions" probably makes more sense.

10. It is difficult to measure the value of wholesale coordination transactions. For the industry as a whole, purchases and sales balance out so that the net revenue attributable to coordination transactions is zero. Roughly 20 percent of the $\mathrm{kWh}$ generated by IOUs is sold to other utilities (primarily other IOUs) in the coordination market. 
integrated utility. Under a requirements contract a selling utility must stand ready to supply all of the net requirements of the buyer for the anticipated duration of the contract. ${ }^{11}$ Requirements transactions are heavily regulated by FERC using fairly rigid cost-of-service principles similar to those used by state commissions regulating retail rates. Wholesale requirements transactions account for about 10 percent of IOU generation and 5 percent of IOU revenues. ${ }^{12}$ The distinction between coordination service and requirements service has become increasingly fuzzy as both integrated and unintegrated distribution utilities have relied more on medium- and long-term nonrequirements wholesale contracts for specific services.

In some cases an economical wholesale transaction can be consummated only with the help of one or more third parties that control transmission facilities. In these cases the buyer must arrange for transmission or wheeling service, a wholesale power transaction subject to the exclusive jurisdiction of FERC. However, FERC's jurisdiction is limited. It can regulate the rates charged for transmission service, but except in extraordinary circumstances it cannot order a utility to provide such service. Thus most transmission arrangements are voluntary, reflecting regulatory and financial incentives, the availability of capacity to serve nonrequirements loads, the historical cooperation between proximate integrated utilities, and the threat of antitrust sanction.

In addition to production by utilities, electricity has always been generated by industrial and commercial establishments, until recently almost exclusively for their own use. In the early years of the electric

11. Such contracts often have notice provisions for termination or firm termination dates. However, FERC has often required utilities to continue to provide service regardless of contractual termination provisions.

12. The status of wholesale requirements customers is somewhat ambiguous. On the one hand, from the perspective of rate regulation and a utility supplier's obligation to serve, they are treated very much like large retail customers. Once a utility takes on a wholesale requirements customer, it is difficult to stop serving that customer even after the contract term expires. On the other hand, a utility does not have an exclusive franchise to serve wholesale requirements customers, and these customers can, in principle, shop among competing suppliers, subject only to the often short notice of termination provisions contained in tariffs approved by FERC. The terms and conditions under which such shopping can take place have been the subject of ongoing regulatory and antitrust controversy between IOUs and publicly and cooperatively owned distribution entities; see J. A. Bouknight, Jr., and David B. Raskin, "Planning for Wholesale Customer Loads in a Competitive Environment: The Obligation to Provide Wholesale Service under the Federal Power Act,'” Energy Law Journal, vol. 8, no. 2 (1987), pp. 237-64. 
power industry, such self-generation was an economically attractive alternative to utility-supplied electricity for many industrial and large commercial users. As recently as 1925 , more than 25 percent of the electricity supplied in the United States came from industrial power plants. But as the cost of large-scale generation and transmission by utilities fell, most industrial customers abandoned self-generation in favor of individually negotiated, long-term power supply contracts with a local utility. By 1978 self-generated electricity constituted only 3 percent of the electricity produced in the United States. Most of the nonutility generating (NUG) capacity had been built to provide all or part of the electricity needs of the establishment that generated the electricity; the facilities usually were not designed to help meet the generation needs of proximate utilities serving other customers. Truly unintegrated independent wholesale power companies owning and operating power plants built to provide generation service under contract to meet some needs of unaffiliated distribution utilities have been virtually nonexistent, and neither state nor federal regulatory policies have contemplated, let alone encouraged, their development until recently. ${ }^{13}$

\section{State and Federal Regulatory Processes}

Public uility companies are organized pursuant to state law and are authorized to do business by the states in which they have facilities and make sales. The terms and conditions of retail franchises are also

13. Electrical World's Directory of Electric Utilities lists nineteen wholesale generating companies. Nine are wholly owned subsidiaries of utilities or utility holding companies and make transactions primarily with affiliated distribution utilities. Six are plants owned by separate corporations, which in turn are jointly owned by distribution utilities that have entitlements to the power they produce. The responsibility for operating these plants is generally placed on one of the joint owners. So in fifteen of the nineteen cases the wholesale power companies are de facto vertically integrated into transmission and distribution since they are owned by distribution utilities. One of the remaining companies is a joint venture between a group of utilities that owns a plant built to provide the requirements of a single customer, a uranium enrichment plant owned by the Department of Energy. Of the three remaining, two are tiny hydroelectric facilities (combined capacity $21 \mathrm{MW}$ ) and one is a company created in 1985 through the spinoff of excess generating capacity owned by Tucson Electric Power Company. In the early history of the industry, independent wholesale power companies, typically created to develop hydroelectric sites, were more common. They generally merged with the distribution utilities to which they sold power. 
determined by state law, and retail rates are regulated by state public utility commissions. Because the typical distribution utility receives nearly all its revenues from retail sales and because generation, transmission, and distribution assets are typically owned by the same corporate entity rather than through common ownership of separate corporate distribution and bulk power (G\&T) subsidiaries, most of a utility's costs are subject to state rather than federal regulatory authority. ${ }^{14}$ Most states also require utilities to obtain certificates of convenience and necessity before building major new generating or transmission capacity, and many review planning procedures for utility construction. ${ }^{15}$

There is no federal regulation of market entry, supply planning, or facility construction in the electric utility industry, except for FERC's authority to issue licenses for hydroelectric sites on navigable waterways under the Federal Water Power Act of 1920 as amended. FERC has no authority to authorize an electric utility to enter the business. And unlike the case of interstate gas pipelines, it has no authority to issue certificates of convenience and necessity to electric power facilities. This is true even if the utility in question engages only in wholesale transactions. FERC's authority is limited to such actions as regulating rates and related terms and conditions for interstate wholesale transactions, establishing a uniform system of accounts, and approving mergers between electric utilities.

A utility must submit to its state commission, in advance of their effective date, any proposed changes in the level or structure of its existing rates as specified in its filed tariffs. The commission then may either allow such changes to go into effect or disallow them in whole or in part subsequent to regulatory review. (Technically the company files new rates that are then suspended by the commission for some period of time.) On its own initiative a commission can also order the utility to

14. If a utility is organized with distribution and generation or transmission assets owned by separate corporate subsidiaries within a holding company framework, transfers of generation and transmission service between the subsidiaries would be wholesale transactions subject to FERC regulation. The transfer prices would appear as purchased power costs to the distribution utility, and the state commission would be obligated to pass them along in retail rates. At least superficially, vertical integration with generation, transmission, and distribution assets owned by the same corporation maximizes state regulatory authority.

15. National Association of Regulatory Utility Commissioners, 1986 Annual Report on Utility and Carriers Regulation (Washington, 1987), pp. 537-49. 
change the level and structure of its rates if they are not consistent with state law. The administrative proceedings in which proposals for changes in price and other conditions of service are made are called rate cases. Prices are fixed between rate cases and until new tariffs are approved by the commission, but some tariffs also have automatic adjustment provisions, generally for fuel and certain expenses for purchased power.

Most state commissions operate under fairly vague statutes mandating that they set "just, reasonable, and nondiscriminatory" rates. State statutes may, however, elaborate more specific criteria as well-that facilities be "used and useful" for their associated costs to be incorporated in rates, for example, or that only "prudently incurred" costs may be included in rates. ${ }^{16}$ Commissions may restrict the use of fuel adjustment clauses, limit the inclusion in rates of construction work in progress, and define criteria for determining the rate base. By and large, the details of regulatory procedures have been defined through the development of regulatory case law, court reviews of regulatory decisions, and rulemaking. In the past few years, however, state legislatures seem to have become more active in revising state statutes to provide more guidance to state commissions.

The basic principle that currently guides state rate regulation is that prices should reflect the cost of service. ${ }^{17}$ For the utility as a whole, prices are in theory set so that total revenues equal total costs or, alternatively, that the average revenue per unit of electricity sold equals the average cost of supplying it. For specific services, such as residential, commercial, and industrial service in different seasons and at different times of day, prices in theory reflect the costs of providing the individual services based on a variety of different cost allocation schemes.

Commissions theoretically set rates so that both operating costs and capital costs are covered. Fuel, labor, materials, and the costs of power purchased wholesale from third parties can be obtained directly from the utility's accounting system if rates are set on the basis of actual costs

16. The "used and useful" principle has been subject to cruel and unusual punishment in recent years as people have tried to use it as a rationale for excluding excess capacity from being covered in rates. Michael W. McConnell, "Public Utilities' Private Rights: Paying for Failed Nuclear Power Projects,'” Regulation, vol. 12, no. 2 (1988), pp. 35-43.

17. The discussion that follows is drawn from Paul L. Joskow and Richard Schmalensee, "Incentive Regulation for Electric Utilities," Yale Journal on Regulation, vol. 4 (Fall 1986), pp. 5-8. 
in a past test year, or they can be estimated fairly easily if a future test year is employed ${ }^{18}$ Capital cost is equal to depreciation plus a fair return on the utility's capital investment stock or rate base. While there was considerable debate earlier in this century as to the proper method for computing capital costs for ratemaking purposes, most commissions now compute it by multiplying an estimate of the utility's nominal cost of capital by the depreciated original cost of its assets. ${ }^{19}$ This latter quantity is called the utility's rate base. Straight-line depreciation is employed, with asset lifetimes that are to some extent arbitrary-and thus the subject of debate from time to time.

This approach to determining capital cost would, if applied exactly and continuously, give the utility a stream of earnings for each asset that has as its present value (using the cost of capital as the discount rate) exactly the original cost of the asset. ${ }^{20}$ Or alternatively the expected rate of return on a utility investment is equal to its cost of capital. Thus in theory the approach provides incentives for utilities to invest (present value of expected cash flows greater than or equal to initial investment cost) and protects consumers from being charged monopoly profits. It is also the case that if rates are continuously adjusted according to these formulas so that the utility earns its cost of capital exactly, then the

18. Two recent Supreme Court decisions make it fairly clear that a state regulatory commission must allow a utility to pass along in retail rates the costs associated with wholesale power purchased pursuant to a FERC-approved wholesale tariff or contract. Mississippi Power \& Light Co. v. Mississippi Ex. Rel. Moore, Attorney General of Mississippi, et al., U.S. Supreme Court, no. 86-1970, June 24, 1988; Nanatahala Power \& Light Co. v. Thornburg, 476 U.S. 953 (1986). See also Narragansett Electric Co. v. Burke (1977) Rhode Island Supreme Court, 381 A2d 1359, cert. denied. 435 U.S. 972 (1979). That is, the state commission must assume that prices charged by the seller are "just and reasonable." A commission may, however, be able to disallow all or part of the costs if it determines that the purchaser was imprudent to enter into the contract in the first place. Pike County Light \& Power Co. v. Pennsylvania Public Utility Commission, Pennsylvania Commonwealth Court, 465 A2d 735 (1983). The circumstances under which a state can do so are uncertain.

19. For the debate see Smyth v. Ames, 169 U.S. 747, 790 (1968); Federal Power Commission v. Hope Natural Gas Company, 320 U.S. 591 (1944); and Duquesne Light Co. et al. v. Barasch et al. U.S. (1989). For current computation methods in the various states, see National Association of Regulatory Utility Commissioners, 1986 Annual Report, pp. 429, 461.

20. Richard Schmalensee, "A Note on Depreciation and Profitability under Rate of Return Regulation,' September 1987, and the references he cites. 
market value of a utility's common equity will exactly equal the book accounting cost value of equity.

Of course, many possible capital-cost accounting formulas that could be used for ratemaking purposes have the property that the expected return on investment is exactly equal to the utility's cost of capital. The particular virtues of depreciated original cost ratemaking of the type traditionally used are primarily accounting simplicity, ease of verifying actual investment costs, and deterring asset transfers designed artificially to inflate the rate base (daisy-chaining). The primary disadvantage, aside from incentive effects, is that the capital cost component of the retail rate charged at any given moment does not generally equal the true economic cost or rental rate associated with the firm's capital at that point; accounting capital costs and economic carrying charges are equal only by chance. ${ }^{21}$

In practice, regulation does not follow these ratemaking principles either exactly or continuously. Two important practical features of electric utility ratemaking are worth noting. First, commissions do not continuously adjust prices as costs change; rates are changed only on the motion of the company or the commission and after often lengthy hearings. Prices (or more precisely the provisions of filed tariffs) may remain unchanged for years, as they did during the 1950s and 1960s for some utilities. This tendency of regulated rates to adjust slowly to changes in costs, frequently referred to as regulatory lag, may cause actual rates of return to be above or below the fair rate of return determined by the commission. Moreover, when prices are fixed, utilities can increase profits by cutting costs; there would be no such incentive if prices were continuously adjusted so that costs incurred would be recovered at every instant.

A second practical feature of ratemaking is that commissions are not bound to set rates that cover all costs incurred by regulated firms. Regulators have the authority to disallow both capital and operating costs if they find the expenditures imprudent or not "used and useful." In principle a commission can disallow certain costs if it believes the utility could have obtained the corresponding services more cheaply or

21. Stewart C. Myers, A. Lawrence Kolbe, and William B. Tye, "Inflation and Rate of Return Regulation,' 'in Theodore E. Keeler, ed., Research in Transportation Economics, vol. 2 (JAI Press, 1985), pp. 83-119, and the references they cite. 
did not require them at all. While a state has considerable flexibility to define the regulatory rules that will apply, the effect of the application must be consistent with constitutional guarantees against taking private property without just compensation. ${ }^{22}$

In addition to setting rate levels (average price for all units sold) and rate structures (prices for specific classes of customers and services), commissions establish such terms and conditions of service as line extension requirements, billing procedures, and service quality attributes. They also issue certificates of convenience and necessity to allow the addition of new plant and equipment, supervise franchising and refranchising, approve mergers and acquisitions, and sometimes get deeply involved in supply-side planning and operating issues. These aspects of regulation vary much more from state to state than does the basic structure of price regulation.

Until recently the basic principle governing federal (FERC) regulation of wholesale transactions has been accounting cost of service. However, for wholesale coordination transactions between unaffiliated utilities, this has increasingly become a regulatory fiction. These transactions have been market driven as sellers compete with one another to make sales to proximate utilities; the buyer is under no obligation to buy and the seller under no obligation to sell. Although sellers have generally been required to cost-justify negotiated contracts, the justification has frequently been accomplished through a variety of arbitrary ex post cost-allocation mechanisms. ${ }^{23}$ Over the past decade the FERC staff has been increasingly willing to accept mutually satisfactory negotiated coordination contracts between integrated utilities that are de facto unencumbered by the rigid cost accounting principles used to set retail rates. This flexible regulatory approach has been critical for encouraging the development of an active wholesale market for excess energy and capacity.

FERC sets rates for wholesale requirements service and approves cost allocations between affiliates of interstate holding companies using

22. Duquesne Light Co. et al. v. Barasch et al. U.S. (1989).

23. The typical approach is to structure the transaction in such a way as to get the accounting costs to yield a price sufficiently attractive to induce the buyer to sign a contract in competition with other third party suppliers or internal production by the buyer. This can be accomplished by structuring the contract so that it associates the output with a mix of generating plants whose accounting costs yield the prices that the buyer is willing to pay. 
embedded cost-of-service ratemaking principles similar to those the states use to set retail rates. An allocation of accounting costs between FERC and retail jurisdictions is made based on the characteristics of their respective loads on the system, including peak load, voltage at which power is taken, and load factor. A depreciated original-cost rate base, nominal cost of capital, and straight-line depreciation are used to determine capital costs. Fuel and nonfuel operation and maintenance costs, taxes, and so forth are added in much the same way as they are at the retail level.

This state and federal regulatory structure (including the Public Utility Holding Company Act of 1935) has evolved in the context of vertically integrated IOUs that are primarily in the business of providing service to retail and captive wholesale requirements customers. Aside from the relatively recent developments affecting the prices that cogenerators and small power producers can charge under PURPA and the implicit regulatory flexibility that has evolved for coordination transactions, FERC never developed, and until recently did not even contemplate, explicit regulatory rules to accommodate unintegrated wholesale power producers competing with one another to build plants generating power for sale under contract to unaffiliated distribution utilities in competitive markets. Despite a lot of rhetoric about competition in wholesale markets, FERC's regulatory policies historically neither encouraged nor accommodated entrepreneurial investments by independent power producers to provide generating service in a competitive wholesale market.

\section{The Traditional System: Rationale and Performance}

The appropriate structure and regulatory environment for promoting the efficient production and pricing of electricity has been the subject of academic debate for many years. ${ }^{24}$ The combination of economies of scale, multiproduct production, and vertical integration provide the primary public interest rationale for the emergence of vertically integrated utilities with de facto legal monopoly franchises to provide retail service to a specific geographical area, subject to price regulation. That

24. Paul L. Joskow and Richard Schmalensee, Markets for Power: An Analysis of Electric Utility Deregulation (MIT Press, 1983), surveys the literature and analyzes several deregulation scenarios. 
is, according to this public interest rationale, the distribution of electricity in any geographical area is a natural monopoly; transmission functions, broadly defined, are natural monopolies over even larger geographical areas; and economies of vertical integration between generation and transmission effectively make the generation required to serve a distribution utility's load efficiently a natural monopoly as well. Thus the optimal organizational form for an electric utility is incompatible with competition in distribution or transmission or with a completely separate generation sector made up of competing firms. These assumptions then lead to the conclusion that regulated integrated monopoly distribution utilities are the efficient institutional response to obtain the cost savings of single-firm production without incurring the costs of monopoly pricing.

What do we know about the natural monopoly characteristics of electricity supply and the performance of regulated integrated electricity monopolies? Is the public interest rationale for the traditional system consistent with the empirical evidence? It is generally acknowledged that the distribution and transmission (encompassing transportation, coordination, and reliability functions) of electricity have natural monopoly characteristics. ${ }^{25}$ There are clearly at least some economies of scale at the level of the generating unit and plant as well. ${ }^{26}$ There also appear to be multiplant economies associated with economical coordination of dispersed generating facilities to meet fluctuating loads and to maintain reliability for a product for which demand varies widely from hour to hour, one that is not storable, and one for which no economical technology is available to signal retail customers with spot prices and thus help balance supply and demand in real time.

The extent of economies of scale in generation per se at the firm level, however, is more controversial. While it is common to talk about generation, transmission, and distribution as if they were separate processes, and while cost and investment data are often broken into these three classifications, they exhibit important technical and economic interdependencies. Furthermore, the characteristics of generation

25. See Joskow and Schmalensee, Markets for Power, pp. 25-77, for a more extensive discussion of the natural monopoly issue.

26. Paul L. Joskow and Nancy L. Rose, "The Effects of Technological Change, Experience, and Environmental Regulation on the Construction Cost of Coal-Burning Generating Units,' Rand Journal of Economics, vol. 16 (Spring 1985), pp. 1-27; and Joskow and Schmalensee, Markets for Power, pp. 45-58. 
and transmission investments, the multiproduct nature of the products supplied by a utility (time of delivery, voltage level, reliability, load factor, and so forth), and the uncertainties of both supply and demand suggest that significant costs may be associated with bilateral contracts efficiently linking investments in and operations of decentralized generation and transmission systems. As a result, the conventional wisdom has been that important economies are likely associated with common ownership of generation and transmission. ${ }^{27}$ In addition, because economies of coordination and reliability associated with an AC transmission network extend over large geographical areas, economies associated with horizontal integration, or extensive cooperation between proximate owners of generating and transmission capacity, are also likely to be substantial. In this regard it is especially important to recognize that significant potential externalities and free-rider behavior are associated with decentralized operation of individual pieces of an interconnected electric power network. Changes in generation, interconnections, or demand at any point in the system have real-time effects throughout an interconnected AC system. These effects are a consequence of physical laws and are not coincident with ownership boundaries or contractual transmission paths.

The available empirical evidence suggests that at the very least the distribution of electricity has important natural monopoly characteristics, which implies that it should continue to be distributed to retail customers by franchised monopoly distribution companies subject to price regulation. While possibilities for competition in distribution, especially to serve large industrial customers, continue to be discussed, policymakers have shown little interest in encouraging competing distributors or in advocating broad deregulation of retail prices. As a result, in the discussion that follows, I assume that distribution will continue to be provided by franchised monopolies subject to some form of price regulation. I will focus on changes associated with the growth of competitive wholesale power markets generally and an independent sector supplying generation in particular.

The electric power industry is presently undergoing changes that could increase opportunities and incentives for vertically integrated investor-owned utilities to rely more on competing suppliers to provide

27. Joskow and Schmalensee, Markets for Power, pp. 59-77. 
them with long-term generating capacity when these sources are more economical than utility-owned capacity. Assuming that retail rates continue to be regulated so that the distributor's prices will reflect the total economic cost, including generating costs, of providing efficient service, the benefits and costs of these changes affect retail customers indirectly through their effects on the costs of the distribution utility.

These changes challenge the conventional view that vertical integration between generation, transmission, and distribution, and horizontal integration between interconnected generating plants, represent the most efficient organizational arrangement for supplying electricity. Probably the most fundamental issues associated with the current trend toward deintegration and the development of competitive wholesale generation markets are associated with questions about alternative organizational arrangements. ${ }^{28}$ What really is the most economical organizational form through which the three components of the electricity supply system should be integrated? What are the trade-offs between the potential efficiencies associated with integrated monopoly distribution companies and the potential inefficiencies associated with the institution of regulated monopoly? What are the properties of such second-best organizational arrangements as power pools, other cooperative arrangements, or bilateral contracting that might sacrifice some of the theoretical efficiencies of vertical and horizontal integration in order to reduce some of the inefficiencies of regulation by relying more on competition to allocate generation resources? ${ }^{29}$

From a purely technical or engineering economics perspective important economies of scale and economies of vertical integration are associated with the supply of electricity. Indeed, from this perspective far too many utilities are involved in generation and (especially) trans-

28. Partial deintegration of generation is not inconsistent with increased concentration of transmission and distribution, for example through mergers. Indeed, expanding the boundaries of horizontal control over transmission systems, combined with suitable provisions for wholesale access and pricing, may facilitate economical deintegration of the ownership of generation from ownership of transmission and distribution.

29. In this regard I should point out that the current structure of the electric power industry is inconsistent with this natural monopoly story. If it were consistent, the United States would have far fewer large vertically integrated utilities. Various cooperative arrangements involving multiple utilities have been introduced to achieve the economies of scale and coordination available from electricity supply technology. I do not doubt that mergers of IOUs could reduce costs, but they have not occurred because state and federal regulation places direct and indirect restrictions on them. 
mission and coordination in the United States. But how these technical characteristics influence one's views about the optimal industry and regulatory structure depends on the extent to which the industry actually achieves its technical potential in practice. Do vertically integrated firms subject to regulation minimize costs statically and dynamically? Do regulators set rates in a way that passes the benefits of a firm's production efficiencies on to consumers? Given that electric utilities are insulated from competition and subject to cost-of-service regulation, it is only natural to hypothesize that they face diminished incentives to minimize costs and that the regulated rates they charge may depart from the most efficient (first- or second-best) prices. As a result, much of the scholarly analysis of the industry has focused on the effects of regulation on costs and prices and has examined regulatory and structural changes to reduce inefficiencies. Because most of this literature is discussed elsewhere, I will provide only a brief selective summary here. ${ }^{30}$

By and large, studies that have examined the effects of regulation as it interacts with the current structure of the industry find that electric utilities do not minimize costs in the neoclassical sense that they achieve equality between the marginal rate of transformation of one input for another and the ratio of the associated input prices. Some studies find evidence that electricity production is biased toward the use of capital inputs. Others find it biased toward the use of fuel or labor inputs. At least one study looks for and finds evidence of "X-inefficiency" as well. ${ }^{31}$

The nature and magnitude of these static inefficiencies vary widely from study to study, however, and the accuracy of the results is very uncertain. The studies must necessarily rely on ex post cost data to estimate long-run cost functions, a questionable undertaking for an industry with long-lived capital facilities and uncertain input prices and demand. There is also much less real variation in state regulatory procedures than is reflected in some of the indices typically used to pick

30. For discussions of the literature see Paul L. Joskow and Roger G. Noll, "Regulation in Theory and Practice: An Overview,' in Gary Fromm, ed., Studies in Public Regulation (MIT Press, 1981), pp. 1-65; and Joskow and Nancy L. Rose, "The Effects of Economic Regulation,"' in Richard Schmalensee and Robert Willig, eds., Handbook of Industrial Organization, vol. 2 (North Holland, forthcoming).

31. Frank M. Gollop and Stephen H. Karlson, "The Impact of the Fuel Adjustment Mechanisms on Economic Efficiency," Review of Economics and Statistics, vol. 60 (November 1978), pp. 574-84. 
up variations in regulation. Empirical work is based on data for firms that have similar structures and operate in similar regulatory environments. Data do not exist to compare performance under fundamentally different structural and regulatory arrangements. While the literature does support a presumption of some inefficiencies associated with the supply of electricity, the magnitude and causes of the inefficiencies and reliability of the results are very uncertain. And we do not know if these inefficiencies are of greater magnitude than would be found by applying the same techniques to unregulated industries.

Studies that examine the effectiveness of state regulation in keeping rates close to the cost of service yield fairly consistent conclusions, however. During the late 1950s and the 1960s regulatory lag allowed utilities to earn returns on investment greater than their cost of capital. Since real costs and prices declined throughout this period and since regulatory lag can encourage static and dynamic cost minimization, customers may have been better off than if regulators had tried to match revenues and costs exactly and continuously. ${ }^{32}$ However, I am not aware of any empirical studies that try to show that this regulatory lag was optimal. The pattern changed dramatically in the 1970s: as real and nominal costs of supplying electricity increased, regulatory lag worked to keep prices below the accounting cost of service and earned returns below the cost of capital. ${ }^{33}$ Some of the work focusing on the early 1980s suggests, I believe correctly, that the regulatory process had become so punitive that utilities' incentives to invest in new generating capacity were sharply diminished. ${ }^{34}$

To the extent that any consensus can be drawn from the scholarly literature on the performance of the industry, it points toward regulatory

32. Alvin K. Klevorick, "The Behavior of Firms Subject to Stochastic Regulatory Review,' Bell Journal of Economics and Management Science, vol. 4 (Spring 1973), pp. $57-88$.

33. William H. Greene and Robert H. Smiley, "The Effectiveness of Utility Regulation in a Period of Changing Economic Conditions," in Maurice Marchand, Pierre Pestieau, and Henry Tulkens, eds., The Performance of Public Enterprises: Concepts and Measurement, Studies in Mathematical and Managerial Economics 33 (Amsterdam: Elsevier, 1984), pp. 269-87; and R. H. Smiley and W. H. Greene, "Determinants of the Effectiveness of Electric Utility Regulation,'’ Resources and Energy, vol. 5 (March 1983), pp. 65-81.

34. Federal Energy Regulatory Commission, Regulating Independent Power Producers, pp. 14-23, and the references cited there; and Department of Energy, Energy Security: A Report to the President of the United States, DOE/S-0057 (March 1987), pp. 130-60. 
reforms to improve the way electricity prices are structured, to the desirability of developing better regulatory incentive mechanisms to guard against inefficient production decisions, and to increased cooperation, coordination, and horizontal mergers, rather than simple prescriptions for deregulation of entry and prices. With a few exceptions the literature does not consider in any detailed way or even anticipate the changes in wholesale power markets now taking place. ${ }^{35}$ Nor is the literature particularly helpful in dealing with the difficult issues that arise in efficiently integrating decentralized power producers into a synchronized interconnected $\mathrm{AC}$ power system.

\section{The Changing Structure and Regulation of Electric Utilities}

The structure and regulation of IOUs is changing in several important dimensions. Figure 2 contains a schematic diagram of the evolving IOU. The IOU is much more heavily engaged than it was fifteen years ago (figure 1) in wholesale transactions with other integrated utilities that involve medium- and long-term contracts for energy and capacity. As figure 2 shows, the IOU is a buyer, but obviously at the other side of the transaction is another IOU making the sale. In addition to such contract sales, wholesale transactions have expanded to include trade with Canadian utilities in both the East and West. Thus rather than relying on wholesale transactions with proximate utilities for short-term economy and reliability, utilities with excess generating capacity are increasingly signing medium- and long-term contracts to allow other utilities to derer capacity additions or to displace uneconomical generating capacity. I want to emphasize, however, that most of this trade involves surplus

35. Some work done as early as the 1960s (discussed in Joskow and Schmalensee, Markets for Power, pp. 179-98) explored the possibilities for reorganizing the industry so that unintegrated distribution utilities could rely on competing unregulated suppliers of generation service instead of owning generating capacity themselves. These studies envisioned breaking up the industry into separate generation, transmission, and distribution sectors with a common carrier transmission system facilitating competition between monopoly distributors and generating companies. This model lies behind the reorganization of the electric power industry in the United Kingdom. For more recent work regarding competition in wholesale power markets, see Richard Schmalensee and Bennett W. Golub, "Estimating Effective Concentration in Deregulated Wholesale Electricity Markets,", Rand Journal of Economics, vol. 15 (Spring 1984), pp. 12-26. 
Figure 2. The Evolving Structure of Investor-Owned Utilities

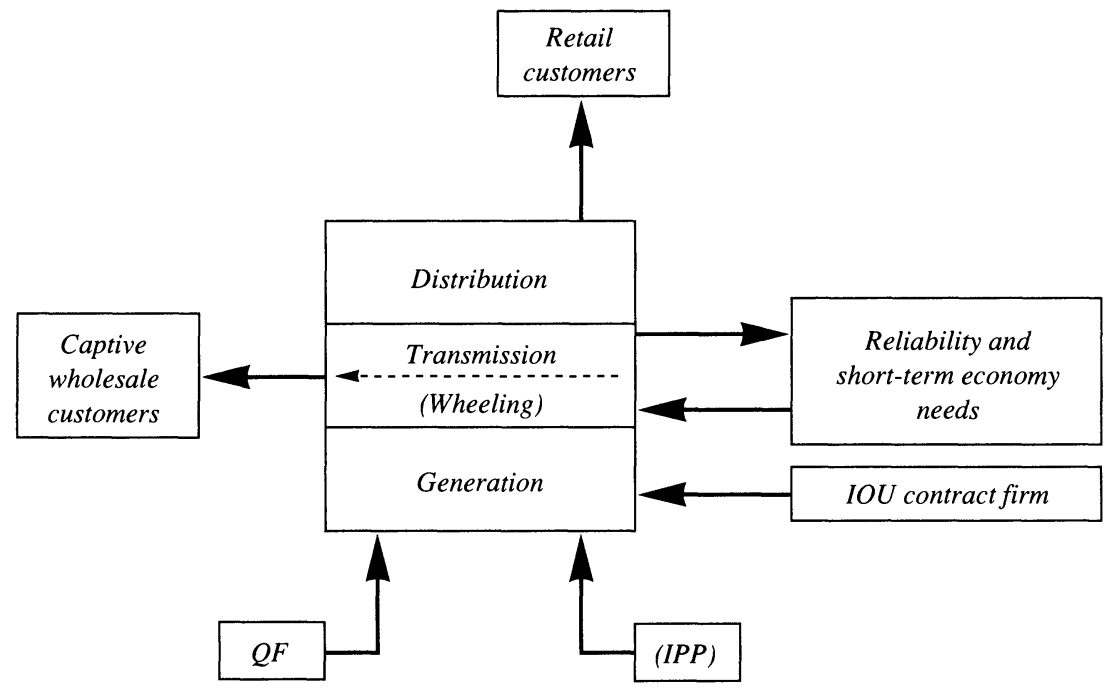

capacity built to meet the expected needs of an integrated utility's requirements customers. The increases in interutility wholesale trade thus far primarily reflect an effort to exploit differences in relative fuel prices and generating capacity that temporarily exceeds the needs of the owners' requirements customers. The capacity associated with this trade was not generally built to serve unaffiliated buyers in the wholesale market, and it will gradually be withdrawn from the market as requirements loads grow.

The second change reflected by the differences in figure 1 and 2 is the introduction of two new categories of suppliers of generation service. The term QF refers to independent cogeneration and small power production facilities that qualify for special regulatory treatment under PURPA. These entities are not subject to cost-of-service regulation; the prices they are paid are supposed to reflect the purchaser's opportunity cost of the type of generation service offered rather than the supplier's cost of service. Supplies of power made available to utilities from QFs (plus QF power used internally by the seller to reduce demands on the utility) have increased significantly in the past few years. More important, QFs are expected to contribute a large fraction of future utility generation requirements. 
The IPP category refers to potential stand-alone producers of generating service built explicitly to supply power to unaffiliated distribution utilities to meet some of their long-term capacity and energy needs. These producers would not be subject to traditional cost-of-service or profit regulation; rather they would negotiate contracts with unaffiliated buyers in competitive markets. IPPs would differ from QFs in at least two ways. First, there would be no requirement that they meet PURPA's technology, fuel, or size limitations. Second, there would be no special statutory requirement that utilities purchase from IPPs. Whether they would do so would depend on the state and federal regulations governing utility procurement practices and the economic advantages that IPPs can offer compared with traditional integrated generation or purchasing from QFs.

At present, IPPs are primarily a gleam in the eye of potential developers, some potential purchasers, and some regulators: few such facilities exist, and current regulations are not particularly conducive to their further evolution. Developments on the fringes of the potential IPP market, however, suggest that evolution. An increasing number of large QFs are really standard power plants that have found minimal contrived steam loads to qualify as QFs. But spending unnecessary money or wasting energy to heat a greenhouse in order to achieve QF status is obviously inefficient, and the developers of these projects would like the opportunity to supply electricity at wholesale without having to go through such motions. There is clearly a growing interest in making the regulatory changes necessary to allow suppliers that are not QFs to offer generation service unencumbered by cost-of-service rate regulation.

The increase in wholesale trade has also been associated with increases in transmission or wheeling arrangements that make it possible to move power from supplier to purchaser when they are not directly interconnected with one another.

Table 1 summarizes the changes in electricity consumption and wholesale transactions of various types from 1973 to 1985 , a period with rising oil and gas prices, and from 1985 to 1986, when the wholesale market responded competitively to the dramatic decline in oil and gas prices. Electricity consumption increased by 32 percent between 1973 and 1985, but wholesale trade of all kinds increased much more. After 1985 short-term interchanges between domestic utilities and Canadian suppliers, and associated wheeling service, declined as lower oil and gas 
Table 1. Change in Wholesale Electric Power Transactions, by Type, 1973-85, 1985-86 Percent

\begin{tabular}{lrr||lrr}
\hline \multicolumn{1}{c|}{ Transaction } & $1973-85$ & $1985-86$ & \multicolumn{1}{c}{ Transaction } & $1973-85$ & $1985-86$ \\
\hline Short-term interchange & 60 & -21 & Wheeling & 290 & -32 \\
Longer-term contracts & 56 & 2 & Purchases from NUGs & 318 & 44 \\
Canadian supplier & 270 & -12 & $\begin{array}{l}\text { Total sales to ultimate } \\
\text { customers }\end{array}$ & 32 & 2 \\
\hline
\end{tabular}

Source: Energy Information Administration, Financial Statistics of Selected Electric Utilities 1986, DOE/EIA0437 (Department of Energy, 1988, and previous years).

costs made these transactions less economical. Longer-term contracts and purchases from nonutility generators continued to increase, however, reflecting longer-term trends in the market. Overall, since 1973 utilities have come to rely more on wholesale trade to meet the needs of their retail customers.

In addition to these structural changes, important regulatory changes have occurred in the past fifteen years. Before the early 1970 s the regulatory process presided more or less passively over a period of rapidly increasing productivity, declining prices, rapidly expanding loads, good financial performance, strong incentives for utilities to invest in new capacity to meet expanding loads, and little political controversy. It has been transformed into a very activist regulatory process with heavy regulatory involvement in the review of costs and operating performance, frequent cost disallowances, regulatory involvement in utility planning, the introduction of incentive mechanisms designed to increase efficiency, ${ }^{36}$ new power supply procurement processes, increasing prices, declining productivity, poor financial performance of utilities, strong disincentives for utilities to invest in new generating capacity themselves, and substantial political controversy. Whether "the regulatory compact has been broken" or not, it has certainly changed dramatically, and not always for the better.

A final change worth noting is the increasing importance of competition of a sort at the retail level. There has been little if any movement toward changing the status of distribution utilities as exclusive retail suppliers. ${ }^{37}$ However, even an exclusive supplier cannot charge a customer any price it chooses. Electricity demand is particularly price

36. For incentive mechanisms see Joskow and Schmalensee, "Incentive Regulation for Electric Utilities."

37. Industrial customers have also exerted pressure for retail wheeling. They have met with little success, and I will not discuss this issue further here. 
elastic in end uses where switching fuels is likely to be economical, in industries where cogeneration is economically attractive, an in industries where production can be relocated to areas with lower electricity prices. Economic and regulatory changes have increased the threat of selfgeneration in particular, and this has tended to moderate rates for certain classes of large industrial customers. It may have led to higher rates for other customer classes, however.

\section{Economic and Political Pressures for Structural and Regulatory Changes}

The motivation for regulatory and structural change in the electric power industry cannot be found in a consensus about performance problems or the specific solutions to them that evolved along with the industry after World War II. Consensus does not exist. While there has been substantial academic analysis of the performance of the industry, it has not led to the kinds of strong conclusions regarding the effects of regulation and the desirability of deregulation or specific regulatory reforms that has been the case in the airline, trucking, railroad, and (perhaps) telecommunications industries. Rather, the structural and regulatory changes taking place are a consequence of uncoordinated regulatory and political fire fighting responses to the turmoil caused primarily by the economic shocks the industry experienced during the past fifteen years.

Changes in regulatory procedures began in the late 1960 s as rising costs led to more and more requests for rate increases and formal hearings. However, the changes were fairly modest responses to inflation and growing concerns about the effects of electricity generation on the environment. It was the economic shocks of the 1970s, in particular after 1973, that led to economic and political turmoil and resulting pressures for change. These shocks included large increases in fossil fuel prices in 1974-75 and again in 1979-80 (figure 3) and new environmental constraints on air and water emissions from power plants that increased the costs of building and operating fossil-fired plants. ${ }^{38}$ Unexpectedly costly nuclear power plants (table 2) and opposition to nuclear power based on

38. Frank M. Gollop and Mark J. Roberts, "Environmental Regulations and Productivity Growth: The Case of Fossil-Fueled Electric Power Generation,'” Journal of Political Economy, vol. 91 (August 1983), pp. 654-74; and Joskow and Rose, "Effects of Technological Change.' 
Figure 3. Utility Fuel Acquisition Costs, 1961-87

Price (cents per million BTU)

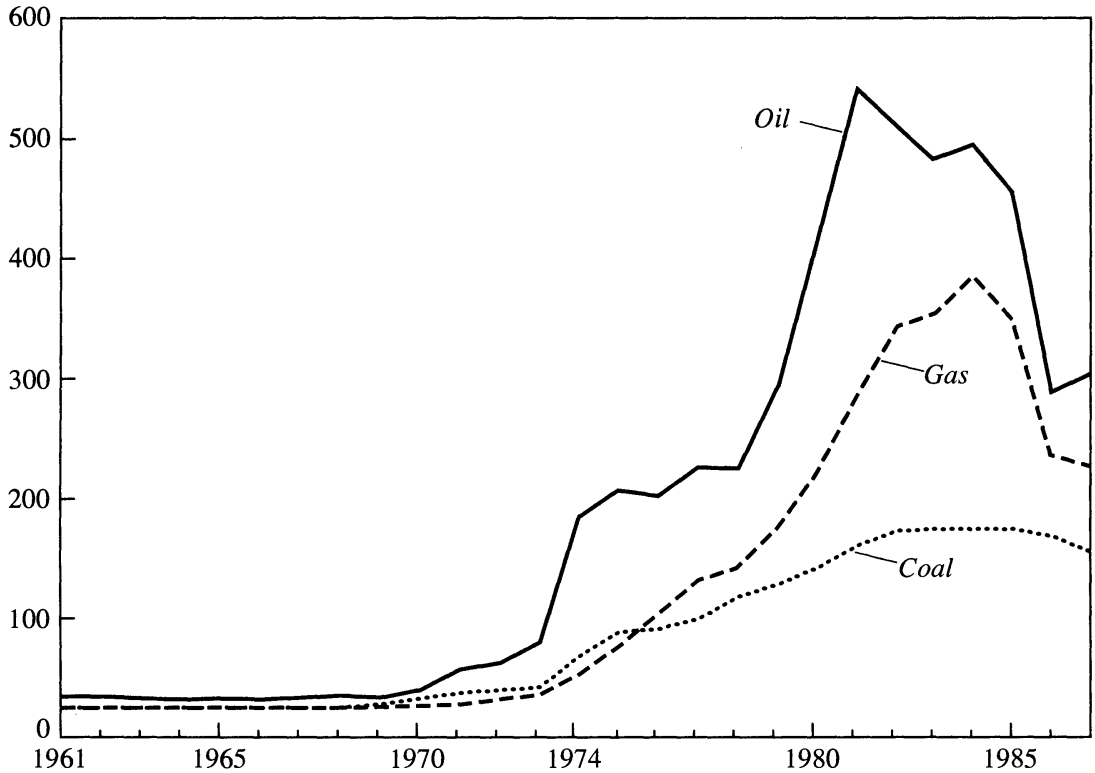

Sources: 1961-70: Edison Electric Institute, Historical Statistics of the Electric Utility Industry through 1970, no. 73-34 (New York, April 1974), p. 116. 1971-86: Edison Electric Institute, Statistical Yearbook of the Electric Utility Industry, 1986 (Washington, 1987), pp. 35, 37. 1987 (gas and coal): Edison Electric Institute, Statistical Yearbook of the Electric Utility Industry, 1987 (Washington, 1988), p. 37.

economic, environmental, and safety concerns were also important, as were an increase in the general rate of inflation and high interest rates. Finally unanticipated reductions in the rate of growth of demand (the annual compound rate of growth in electricity consumption dropped from 7.3 percent a year between 1960 and 1973 to 2.5 percent a year between 1973 and 1985)resulted in substantial excess generating capacity (figure 4). ${ }^{39}$ These economic shocks fell heavily on the generation component of electricity supply, which accounted for 75 percent of

39. A utility's reserve margin is equal to the difference between its nominal generating capacity and the peak load on the system divided by the peak load on the system. Generating capacity must be built to meet expected peak demands. As a consequence of uncertain demand, scheduled and unscheduled equipment outages, and uncertain construction schedules, maintaining a high level of reliability requires that a utility maintain a significant reserve margin. A very rough rule of thumb for a modern utility interconnected with its neighbors is 20 percent. Since generating capacity investments are lumpy, and since capacity has long construction periods and demand is uncertain, actual reserve margins will generally be higher or lower than this target. 
Table 2. Average Nominal Construction Cost of Nuclear Electrical Generation Units, 1968-87

Dollars per $\mathrm{kW}$

\begin{tabular}{cc||cc}
\hline $\begin{array}{c}\text { Period units } \\
\text { entered service }\end{array}$ & Cost & $\begin{array}{c}\text { Period units } \\
\text { entered service }\end{array}$ & Cost \\
\hline $1968-71$ & 161 & $1979-84$ & 1,373 \\
$1972-73$ & 217 & 1985 & 2,466 \\
$1974-75$ & 404 & 1986 & 2,765 \\
$1976-78$ & 623 & 1987 (estimated) & 3,776 \\
\hline
\end{tabular}

Source: Energy Information Administration, Nuclear Power Plant Construction Activity, 1986, DOE/EIA-0473 (Department of Energy, August 1987), p. 13.

operation and maintenance costs and 65 percent of capital costs in 1986. As a result, the pressures for regulatory and structural changes have focused on generation.

Before 1968 rising input costs were generally more than compensated for by real cost savings resulting from scale economies, increased coordination between systems, or opportunities to improve the thermal efficiency of generating units using conventional steam-turbine technology..$^{40}$ By 1970 , however, as input price increases began to accelerate, productivity growth resulting from fuller exploitation of economies of scale, better coordination, and technological innovation stagnated. Nominal and real costs of supplying electricity began to increase rapidly, which led utilities to file for large rate increases with state and federal regulatory agencies.

I argued many years ago that the regulatory process works in such a way that electricity prices are "sticky" both downward and upward in response to changes in nominal costs. The process is especially resistant to price increases requiring administrative approval. To reflect rising costs in rates, utilities repeatedly had to seek approval for large rate increases. These applications were set for formal hearings, which provided a forum for those adversely affected by the price increases to oppose them. Not surprisingly, large rate increases were aggressively resisted by groups representing customers, by their political agents in the legislative and executive branches, and ultimately by regulators appointed by governors (or in a few states elected directly) and responsible to legislatures. In the end, utilities had a very difficult time

40. Paul L. Joskow, "Productivity Growth and Technical Change in the Generation of Electricity," Energy Journal, vol. 8 (January 1983), pp. 17-38; and Joskow and Richard Schmalensee, "The Performance of Coal-Burning Electric Generating Units in the United States: 1960-1980,' Journal of Applied Econometrics, vol. 2 (April 1987), pp. 85-109. 
Figure 4. Average U.S. Electric Reserve Margin, 1960-87 ${ }^{\mathrm{a}}$

Reserve margin (percent)

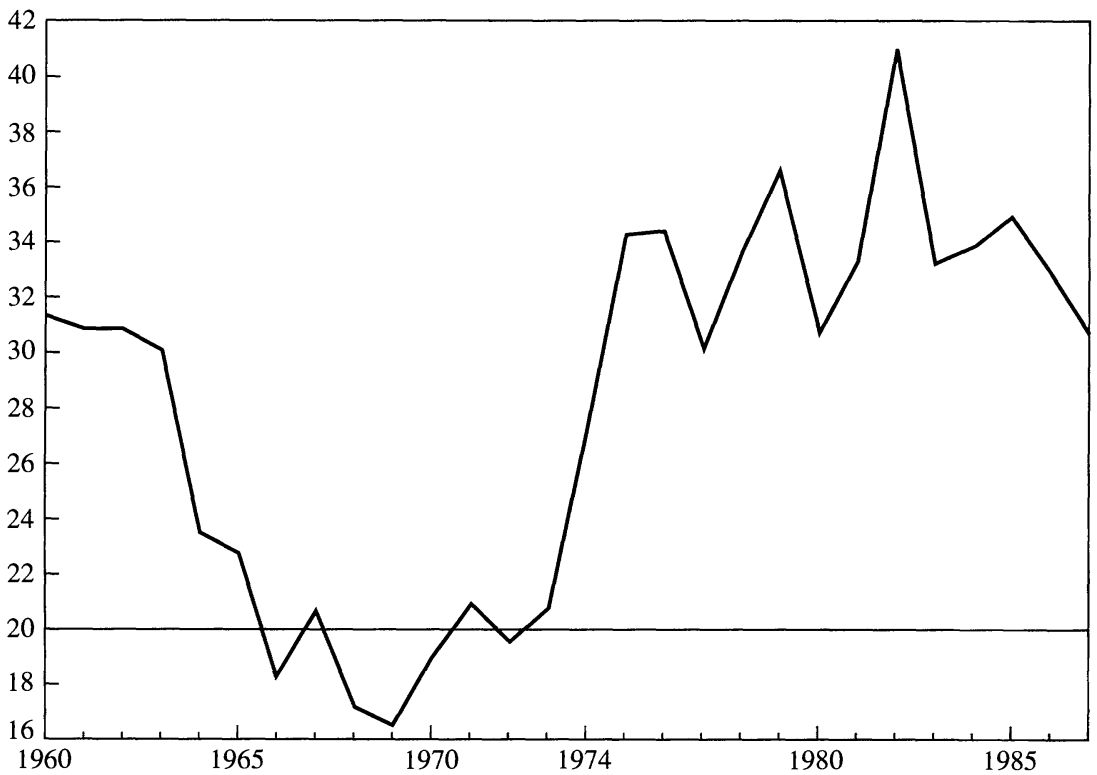

Sources: Edison Electric Institute, Statistical Yearbook of the Electric Utility Industry, 1987, p. 14; and Edison Electric Institute, Historical Statistics of the Electric Utility Industry through 1970, p. 20.

a. Average U.S. reserve margin is computed as the difference between the generating capability at the time of summer peak load and the noncoincident summer peak load divided by the noncoincident summer peak load.

recovering the costs they had expected would be afforded traditional cost-of-service treatment through the ratemaking process.

One can get a feeling for the nature and magnitude of the economic shocks and the regulatory responses to them by examining patterns of electricity prices, rate increases approved by state regulators, and industry financial performance before, during, and after the 1970s.

Figure 5 shows the nominal price per $\mathrm{kWh}$ in the United States from 1960 to 1987 averaged over all consumer groups and for the residential and industrial classes separately. Figure 6 shows prices in constant dollars. The nominal and real average price per kWh fell almost continuously between 1960 and 1970 . Nominal prices began to rise in 1970 and took big jumps after 1973 and 1979. Real electricity prices show a similar pattern. By 1985 nominal and real prices began to decline as fossil fuel prices, interest rates, and the general rate of inflation declined and capacity utilization began to increase. 
Figure 5. Nominal Price of Electricity, 1960-87

Price (cents per $k W h$ )

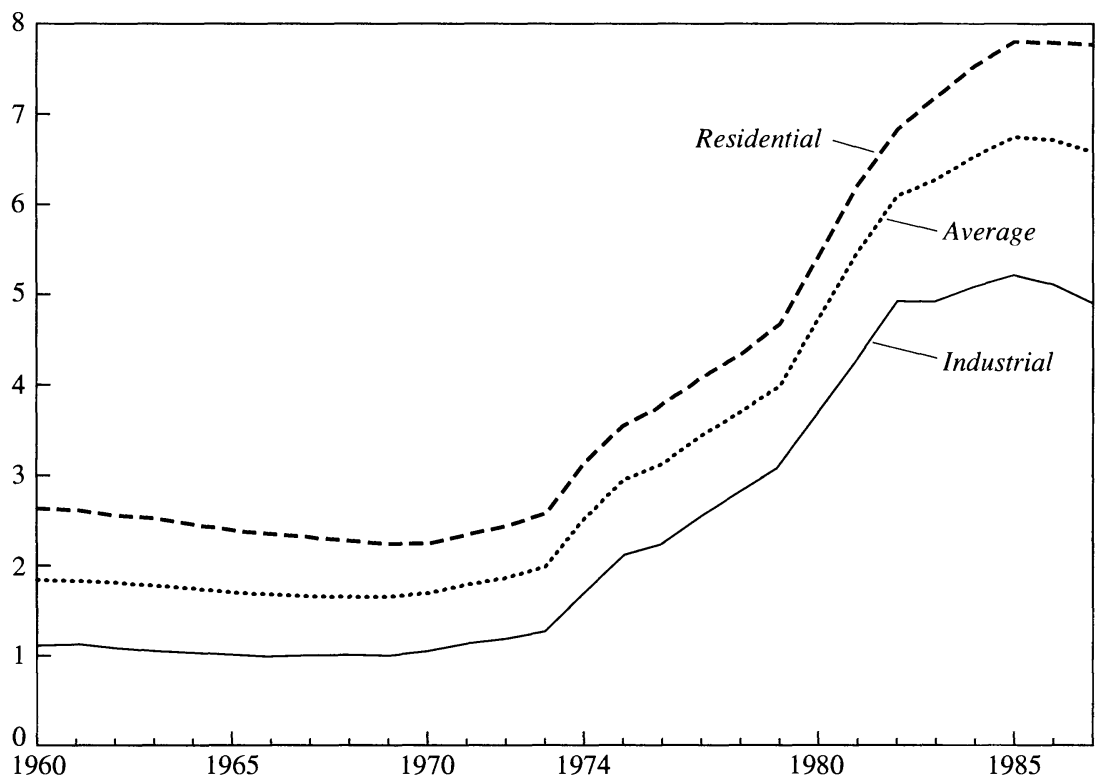

Source: Edison Electric Institute, Statistical Yearbook of the Electric Utility Industry, 1987, table 64.

Another way to look at the responses to cost increases is to examine the pattern of base rate increases or decreases approved by state regulatory authorities (figure 7). Until 1969 there were no net base rate increases; indeed there were decreases. After 1969 applications for rate increases and regulatory commission approvals began to increase, with big jumps after 1973 and again after 1979. Requests fell off sharply after 1985 as interest rates declined, inflation abated, capacity utilization increased, and utility generating capacity construction programs came to an end.

The electric power industry had not experienced sustained cost increases and repeated formal rate hearings to pass on rate increase requests since state commission regulation was widely introduced in the early decades of the century. ${ }^{41}$ Historically, there had been few formal

41. Nominal electricity prices declined continuously from at least 1925 until 1970. See Edison Electric Institute, Historical Statistics of the Electric Utility Industry through 1970, no. 73-34 (New York: April 1974), p. 165. 
Figure 6. Real Price of Electricity, 1960-87

Price (cents per $k$ Wh in 1982 dollars)

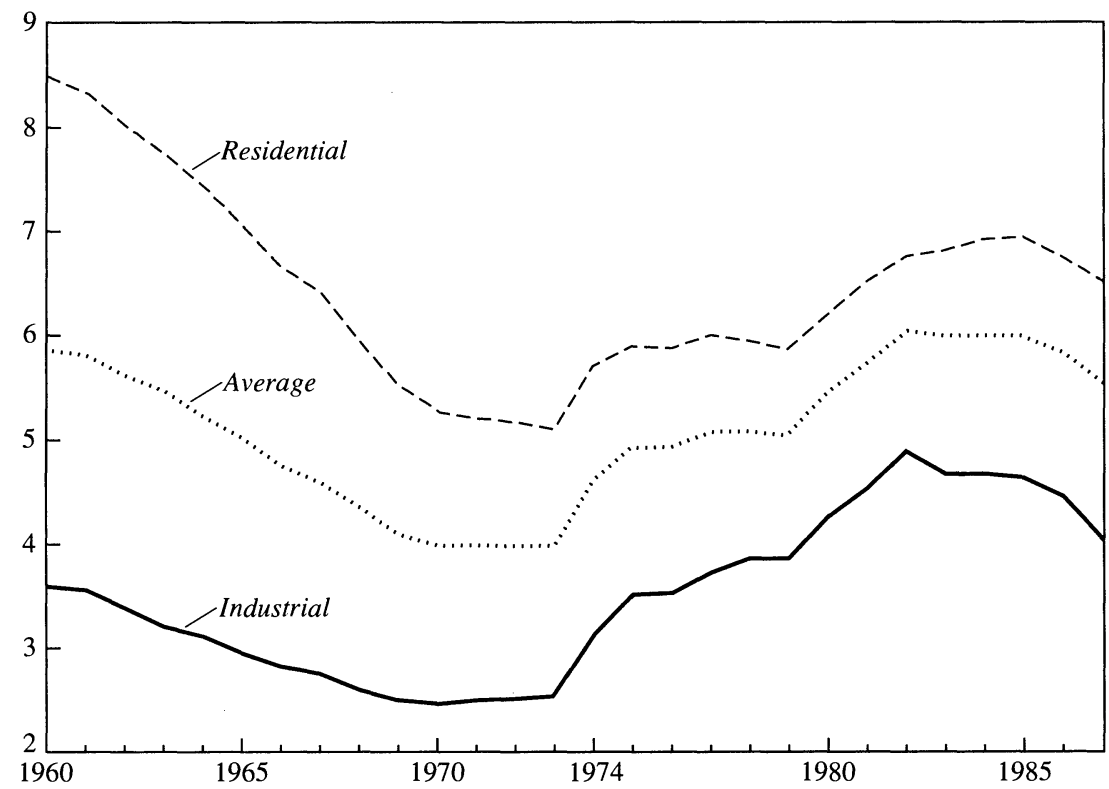

Source: Edison Electric Institute, Statistical Yearbook of the Electric Utility Industry, 1987, table 64, data adjusted by the GNP deflator $(1982=100)$.

rate cases, little public intervention in rate cases to consider rate increase requests, and extensive reliance on informal moral suasion by regulators to bring about rate reductions. The regulatory process that had evolved was not designed to deal with large and continuing cost increases and the controversies spawned by utilities' requests to pass the costs along in higher prices.

The "regulatory resistance" view I subscribe to suggests that large increases in nominal costs should have been accompanied by reduced profitability for utilities after 1968 and in particular after 1973 as price increases lagged behind cost increases. One should also see a recovery beginning about 1984 as the cost pressures abated or reversed. A variety of indicators can suggest how utilities performed financially before, during, and after these cost shocks. These include the earned rate of return on equity investments (calculated symmetrically with the way allowed rates of return are calculated) relative to the cost of capital, interest coverage levels, the ratio of a utility's common stock price to the book value per share of equity invested, and the proportion of book 
Figure 7. Average Net Annualized Electricity Rate Increases Authorized by State Regulators, 1963-87 a

Billions of dollars

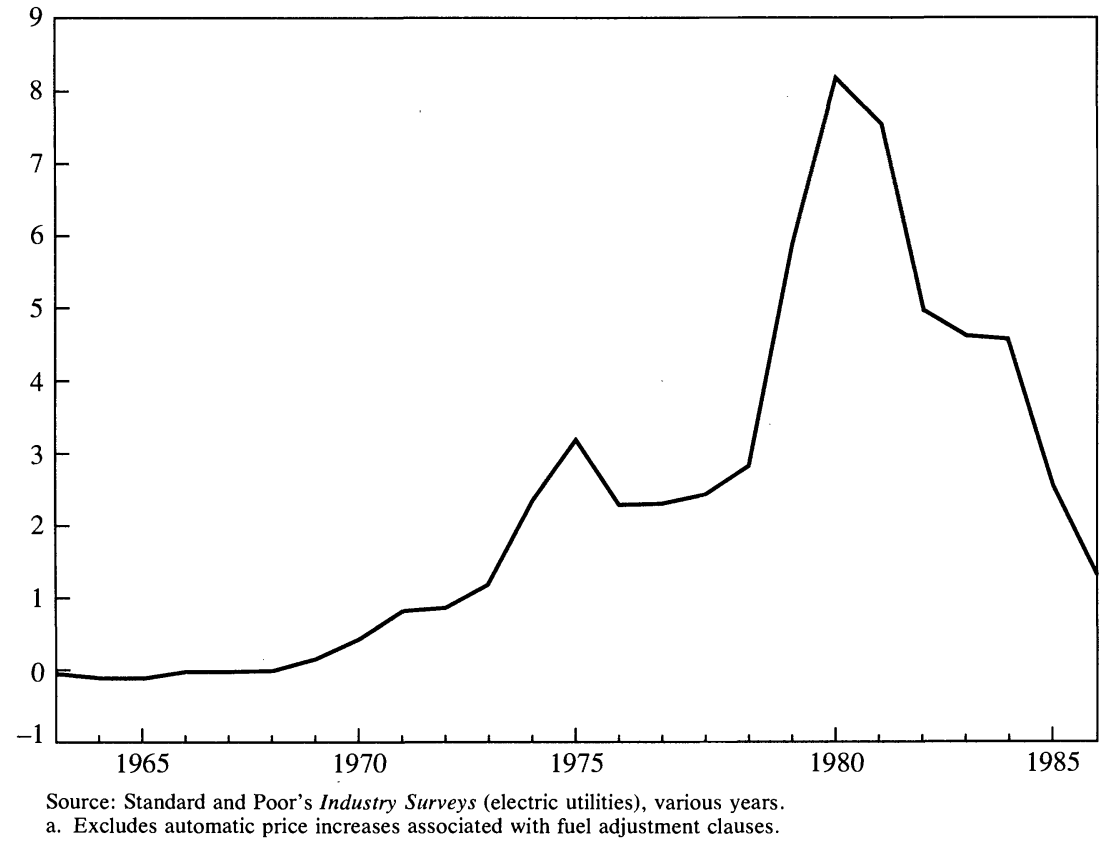

earnings that are cash earnings. ${ }^{42}$ Table 3 shows several of these indicators of the financial performance for the twenty-four utilities in Moody's electric utility average from 1960 to 1987.

Between 1960 and 1968 utilities performed well financially. Earned rates of return on equity were far above the average cost of new debt, virtually all the earnings reported were cash earnings, price-book ratios were significantly greater than one, and interest coverage ratios were

42. In theory if a regulatory agency relies on a depreciated original cost rate base and allows a utility to earn exactly its nominal cost of capital, the price-to-book ratio should be equal to 1.0. Because of the mandatory normalization of certain income tax benefits for ratemaking purposes, if regulation is working perfectly, the ratio should be about 1.1 for a typical utility. A ratio less than 1.0 implies the utility is expected to earn a return on its investment that is less than its cost of equity capital. A ratio significantly greater than 1.0 means that the market expects a utility to earn significantly more than its cost of equity capital.

Regulated utilities operate under special accounting rules issued by the Financial Accounting Standards Board as adopted by the SEC, FERC, and state commissions. Of 
Table 3. Electric Utilities Financial Performance, 1960-87 ${ }^{\text {a }}$

Percent unless otherwise specified

\begin{tabular}{|c|c|c|c|c|c|c|}
\hline Year & $\begin{array}{l}\text { Return } \\
\text { on } \\
\text { equity }\end{array}$ & $\begin{array}{c}\text { Yield on } \\
\text { new } \\
\text { utility } \\
\text { debt }\end{array}$ & Difference & $\begin{array}{c}\text { Price- } \\
\text { book } \\
\text { ratio }\end{array}$ & $\begin{array}{l}\text { Earnings } \\
\text { AFUDC }^{\mathrm{b}}\end{array}$ & $\begin{array}{c}\text { Interest } \\
\text { coverage }^{\mathrm{c}}\end{array}$ \\
\hline 1960 & 10.20 & 4.72 & 5.48 & 1.73 & 6.55 & 5.11 \\
\hline 1961 & 10.30 & 4.72 & 5.58 & 2.15 & 5.77 & 5.13 \\
\hline 1962 & 10.70 & 4.40 & 6.30 & 2.06 & 5.07 & 5.22 \\
\hline 1963 & 10.80 & 4.40 & 6.40 & 2.22 & 3.61 & 5.23 \\
\hline 1964 & 11.10 & 4.55 & 6.55 & 2.22 & 4.07 & 5.20 \\
\hline 1965 & 11.70 & 4.61 & 7.09 & 2.31 & 4.56 & 5.18 \\
\hline 1966 & 12.10 & 5.53 & 6.57 & 1.97 & 5.40 & 4.97 \\
\hline 1967 & 12.20 & 6.07 & 6.13 & 1.98 & 7.80 & 4.49 \\
\hline 1968 & 11.50 & 6.80 & 4.70 & 2.02 & 10.19 & 4.06 \\
\hline 1969 & 11.40 & 7.98 & 3.42 & 1.70 & 13.87 & 3.50 \\
\hline 1970 & 10.80 & 8.79 & 2.01 & 1.59 & 21.48 & 2.69 \\
\hline 1971 & 10.80 & 7.72 & 3.08 & 1.48 & 26.33 & 2.53 \\
\hline 1972 & 11.00 & 7.50 & 3.50 & 1.34 & 30.27 & 2.58 \\
\hline 1973 & 10.50 & 7.91 & 2.59 & 1.10 & 31.92 & 2.41 \\
\hline 1974 & 10.40 & 9.59 & 0.81 & 1.15 & 35.91 & 2.16 \\
\hline 1975 & 10.30 & 9.97 & 0.33 & 1.06 & 34.23 & 2.20 \\
\hline 1976 & 10.60 & 8.92 & 1.68 & 0.93 & 31.53 & 2.41 \\
\hline 1977 & 11.00 & 8.43 & 2.57 & 0.61 & 29.40 & 2.54 \\
\hline 1978 & 10.70 & 9.30 & 1.40 & 0.64 & 37.37 & 2.53 \\
\hline 1979 & 11.00 & 10.85 & 0.15 & 0.74 & 46.82 & 2.09 \\
\hline 1980 & 10.70 & 13.46 & -2.76 & 0.65 & 56.01 & 1.89 \\
\hline 1981 & 12.40 & 16.31 & -3.91 & 0.68 & 52.85 & 1.95 \\
\hline 1982 & 13.20 & 14.93 & -1.73 & 0.77 & 56.06 & 1.92 \\
\hline 1983 & 14.30 & 12.70 & 1.60 & 0.89 & 51.35 & 2.57 \\
\hline 1984 & 14.90 & 14.25 & 0.65 & 0.84 & 46.99 & 2.67 \\
\hline 1985 & 14.40 & 11.83 & 2.57 & 0.99 & 42.70 & 2.79 \\
\hline 1986 & 14.50 & 9.61 & 4.89 & 1.23 & 32.33 & 3.32 \\
\hline 1987 & 12.70 & 9.75 & 2.95 & 1.18 & 30.39 & 3.08 \\
\hline
\end{tabular}

Source: Moody's Public Utility Manual (Blue Sheets), 2 vols. (New York: Moody's Investors Service, 1988), pp. a13, a14; 1987 figures are author's estimates.

a. Moody's twenty-four electric utility stocks used in average. Book values exclude deferred taxes.

b. Allowance for funds used during construction.

c. Excluding AFUDC.

particular importance is the treatment of plants under construction. In most jurisdictions utilities are not permitted to include construction work in progress in the rate base or are only allowed to include some of it. However, utilities are allowed to book noncash credits, called allowances for funds used during construction (AFUDC), against interest expenses and equity earnings. These credits reduce net book interest costs and increase book equity returns. AFUDC credits are capitalized and included as part of the cost of the plant when (and if) it is completed and placed in the rate base. 
Figure 8. Electric Utility Ratio of Common Stock Price to Book Value, 1960-87

\section{Ratio}

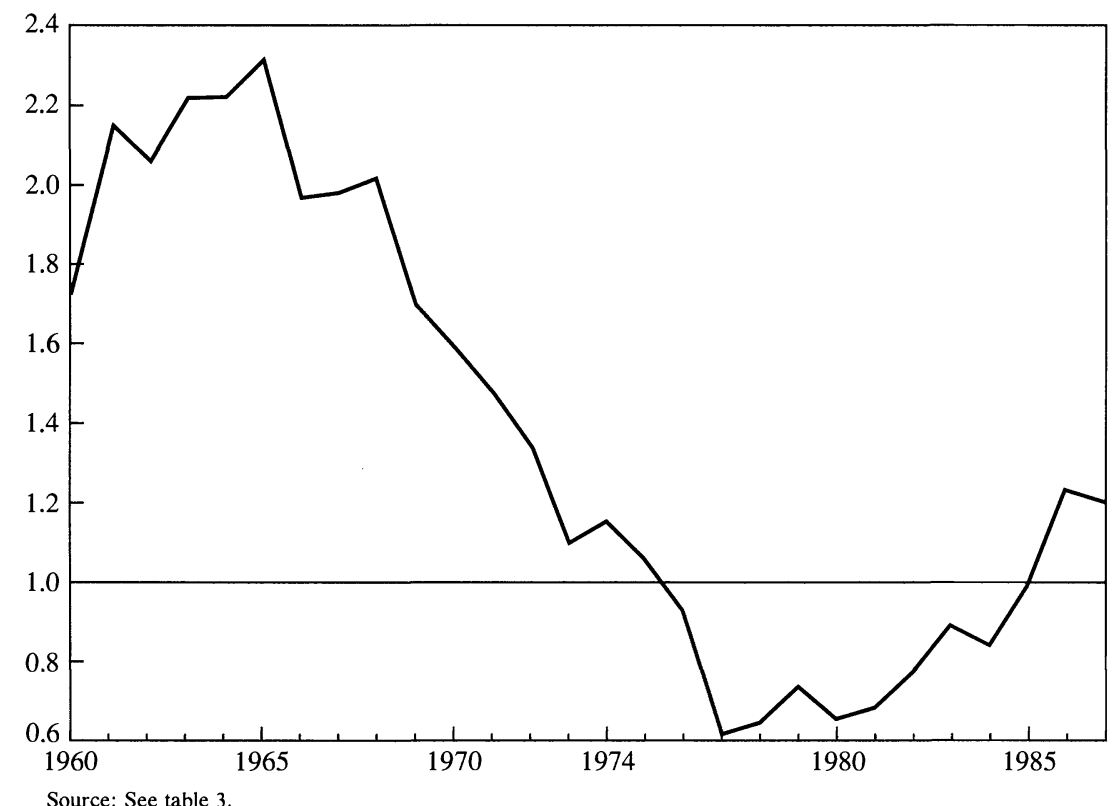

high. But by 1968 the performance was already starting to deteriorate, although the system appeared to be stabilizing in the early 1970s, with earned rates of return approximately equal to the cost of capital. After 1973, however, performance deteriorated dramatically. Common stock price-book ratios fell below one (figure 8), the earned rate of return on equity did not keep up with changes in interest rates, utilities generally failed to earn their allowed rates of return on equity (figure 9), and a growing fraction of earnings were noncash accounting credits, the basis for which was the assumption that generating plants under construction would eventually be given rate base treatment and a return on the associated investment equal to the cost of capital earned. Financial performance began to improve only after 1984 as economic conditions became more favorable and generating capacity construction programs ended. ${ }^{43}$

43. The improvement in the financial health observed for the industry after 1984 is consistent with the idea of "regulatory resistance." As major construction programs ended, fuel prices and interest rates declined, capacity utilization increased, and inflation abated, utilities benefited once again from regulatory lag, although regulatory agencies 
Public utility regulation is often characterized as a cost-plus system. But while capital and operating costs are the primary determinants of electricity rates in the long run, the financial experience of the industry in the past twenty years makes it clear that it is not a pure cost-plus system.

How exactly did the regulatory process "resist" price increases? At first, it simply relied on the natural inertia in conventional procedures. It takes at least a year to put a rate filing together and to get a state commission to render a decision. And since many commissions still rely on a historical test year, new rates might go into effect based on costs that are at least two years old (although automatic fuel cost adjustment clauses could cushion the lag). The effects of regulatory lag per se can be seen by examining the relationship between the average rate of return on equity allowed by regulatory agencies in a particular year and the rate of return on equity actually earned by utilities in that year. The allowed rate of return is supposed to reflect the utility's current cost of equity capital, so earned and allowed rates of return should be approximately equal at least on average over a period of a few years.

Figure 9 shows the relationship between allowed and earned rates of return from 1974 to 1988 . Earned rates are substantially below the allowed rates during most of this period. The gap disappears only after 1985 as fuel prices decline, inflation and interest rates decline, and generation construction programs come to an end. Although comparable data for the pre-1974 period are not available, my earlier work suggests that the earned rate of return was greater than or equal to the cost of capital before the mid-1970s. ${ }^{44}$ The relationship between allowed and earned rates of return in figure 9 is also completely consistent with the behavior of utility common stock price-book ratios (figure 8).

Regulators initially tried to respond to the pressures they were subjected to with various modest and often sensible regulatory innova-

seem to have been quicker to require rate adjustments to reflect lower costs than they were to have them reflect higher costs. Improved financial health is not universal, however. Utilities that still have incomplete nuclear projects, or have not yet resolved the ratemaking treatment of recently completed nuclear plants, exhibit poor financial performance, as do utilities with significant excess capacity or industrial customers with good self-generation opportunities.

44. Joskow, "Pricing Decisions of Regulated Firms"; and Joskow, "Inflation and Environmental Concern,” pp. 305-11. 
Figure 9. Allowed and Earned Rates of Return on Equity for Electric Utilities, 1974-88 Rate of return (percent)

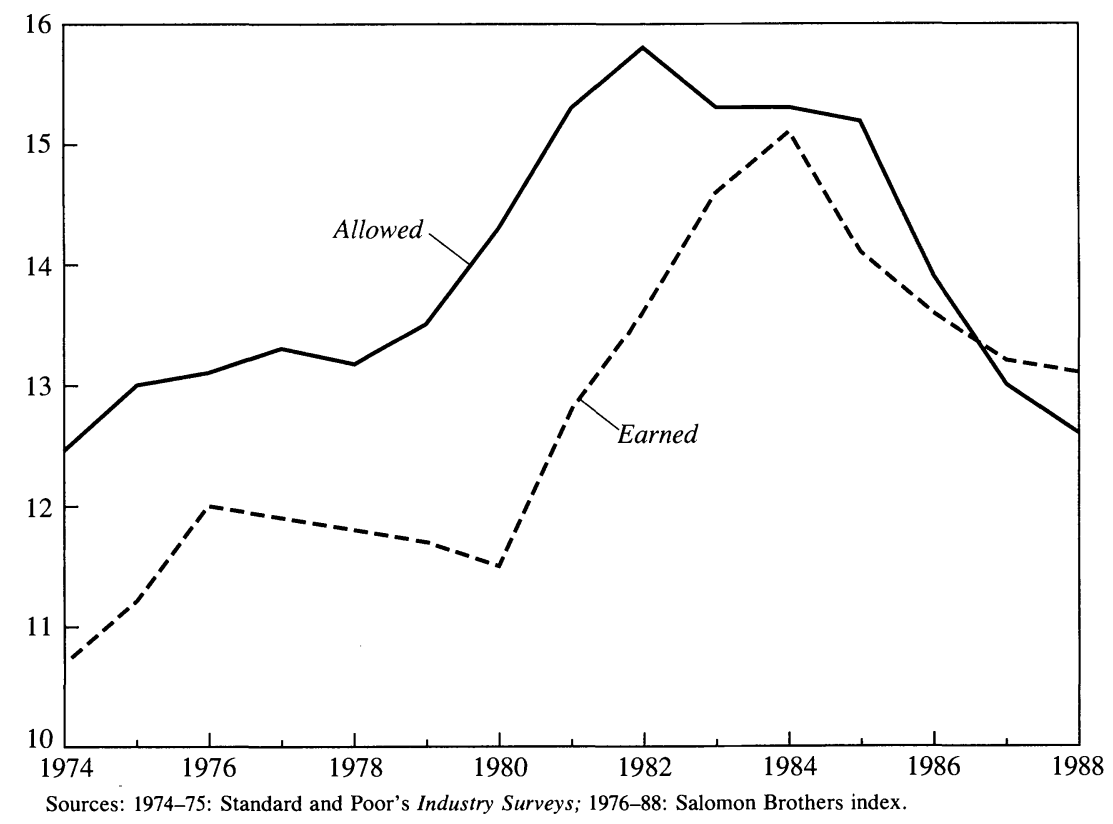

tions that did not depart significantly from established principles. For example, they came to understand that using a depreciated original-cost rate base plus a nominal cost-of-capital-based rate of return tends to front-load revenue requirements. This leads to rate shocks when inflation is rapid, nominal interest rates are high, and capital additions come in big lumps. ${ }^{45} \mathrm{~A}$ variety of phase-in mechanisms were applied as a reasoned response designed to avoid rate shock. State regulators also became much more sensitive to the potential disincentives for efficiency resulting from cost-plus regulation. This led some regulators to experiment with formal incentive mechanisms applied primarily to the performance of generating units. ${ }^{46}$

However, none of the innovations fully responded to the political pressures to insulate consumers from cost increases. And in the late 1970 s and early 1980 s costs and rate increase requests escalated as

45. Myers, Kolbe, and Tye, "Inflation and Rate of Return Regulation.",

46. Joskow and Schmalensee, "Incentive Regulation for Electric Utilities." 
utilities continued to build nuclear and coal-burning generating plants in anticipation of future capacity needs or to replace uneconomical oil and gas-fired facilities. ${ }^{47}$ These plants turned out to be much more costly than had been anticipated, with costs per kilowatt far greater than the average embedded cost of plant in rate base. When completed they would have caused significant increases in the size of the rate base on which capital charges are based, if traditional cost-of-service principles had been applied. Some of the most costly plants began to enter service after 1979 in the face of a growing surplus of generating capacity, rapidly rising fuel prices, rising interest rates, and an increase in the general rate of inflation (see figures 5 and 6 and table 2). Giving these new plants conventional rate-base or cost-of-service treatment often implied large rate increases on top of rapid increases in fuel prices and other operating costs. As a result, regulatory commissions came under considerable pressure to resist including the costs of the plants in the rates.

Many regulatory commissions responded by subjecting new power plants to ex post "prudence" reviews. ${ }^{48}$ Although between 1945 and 1975 there were fewer than a dozen prudence cases, such reviews have now become a routine component of the regulatory process. ${ }^{49}$ Virtually all nuclear plants completed since 1980 have been subject to prudence reviews, and in most cases some part of their total cost has been disallowed. ${ }^{50}$ When regulatory commissions could not show that invest-

47. Utilities did not just build generating plants under the assumption that higher rates would cover anything they spent. Many power plants being planned or constructed were eventually cancelled, some after substantial expenditures had been incurred, including roughly one hundred nuclear plants announced by utilities before 1975 . Most of the abandonments involving significant sunk costs appear to have occurred after 1979 in response to the Three Mile Island accident, high interest rates, declining demand for electricity, and utilities' financial difficulties. About eighty coal units that were in the planning or construction cycle were either delayed or abandoned as well. It is also misleading to look only at nominal reserve margins. In many cases new coal and nuclear generating plants were economically justified to back out of expensive oil-fired and gasfired generation, rather than to meet short-run capacity needs. The collapse of oil and natural gas prices after 1985 changed this economic calculus significantly.

48. National Regulatory Research Institute, The Prudent Investment Test in the 1980s, RRI-84-16 (Columbus, Ohio, April 1985).

49. Federal Energy Regulatory Commission, Notice of Proposed Rulemaking Re Regulations Governing Independent Power Producers, Docket no. RM88-4-000 (March 16, 1988), p. 13.

50. Federal Energy Regulatory Commission, Regulating Independent Power Producers, pp. 13-21; Department of Energy, Energy Security, pp. 154-57; Alfred E. Kahn and 
ments were imprudent, they have sometimes simply changed the rules of the game, taking the position that cost-of-service compensation would only be provided if the economic value of the plant was greater than its accounting cost, the "used and useful" concept. This made it possible to disallow cost claims caused by excess capacity and unanticipated changes in economic conditions (to the best of my knowledge no regulatory agency has yet rewarded a utility for building and operating plants with accounting costs less than the economic value of the plant). Altogether, utility stockholders probably ate roughly 20 percent of their investments in nuclear power plants, amounting to tens of billions of dollars.

Prudence determinations and associated cost disallowances were largely a political response to a political problem rather than the application of well-established regulatory principles. ${ }^{51}$ However, the repeated necessity of dealing with requests for large rate increases has led to profound changes in the regulatory process, many of which, although motivated by the economic turmoil of the 1970s and early 1980s, have become permanent fixtures. In particular, cost disallowances for generating facilities have become routine, while changes in the ratemaking process to account for the increased risk of disallowances have not been forthcoming.

Utility behavior has naturally responded to the incentives created by the experience of the post-1973 period. Utilities learned that if they built large new generating plants, they might very well not recover their investment: commissions might resist large rate increases even if the increases were fully justified. As a result, the expected return on investments in new generating plants subject to regulation is perceived to be below the cost of capital. Few utilities appear willing to build large base-load facilities, even in areas where additional capacity is needed. ${ }^{52}$ Instead, they are looking to third parties, smaller and less capital-

Lewis J. Perl, "The Historical Regulatory Bargain and the Treatment of Nuclear Plants" (1985); and Douglas Hearth and others, "Regulatory Issues in Nuclear Power Plant Cancellations," Public Utilities Fortnightly, September 1, 1988, pp. 15-19.

51. McConnell, "Public Utilities' Private Rights."

52. Aside from unlicensed or incomplete nuclear plants, utilities that are building anything are generally building much smaller generating units than they did in the past. North American Electric Reliability Council, 1988 Electricity Supply and Demand for 1988-1997 (Princeton, N.J., October 1988). 
intensive generating technologies, and investments in customer conservation to reduce the financial risks. Several commentators have suggested they are now underestimating demand and underinvesting in new capacity. ${ }^{53}$ Without changes in the regulatory environment that make new investments in generating capacity attractive, the long-term consequences of this response will be higher electricity costs and reduced reliability.

The economic problems stimulating regulatory, behavioral, and structural changes were not largely consequences of inherent failures associated with the structure of the industry or the theoretical regulatory principles to which it was subject. Increases in fuel and labor costs, declining economic growth, costly environmental regulations, and excess generating capacity would have occurred whatever the structure of the industry or the way it was regulated. Exactly the same problems affected integrated government and cooperatively owned utilities in the United States and utilities in other countries despite ownership and regulatory differences. However, the industry's structure and the regulatory process did affect the distribution of the burdens of higher costs and provided a political mechanism for affecting that distribution. As a result, the "failure" of the system was largely, though not entirely, a political and administrative failure.

The experience of the 1970s and early 1980s has made it clear that existing industrial and administrative arrangements are politically incompatible with rapidly rising costs of supplying electricity and uncertainty about costs and demand. ${ }^{54}$ The inability of the system to deal satisfactorily with these economic shocks created a latent demand for better institutional arrangements to regulate the industry, in particular to regulate investments in and operation of generating facilities. The existence of excess capacity gave regulators, utilities, and other interest groups an opportunity to "hold up" utility investors and to come up with alternatives before the disincentives to invest in new capacity were revealed as a supply shortage. The excess capacity is rapidly disappear-

53. Department of Energy, Energy Security, pp. 154-57, and Federal Energy Regulatory Commission, Regulating Independent Power Producers, pp. 13-23, and the references they cite.

54. Federal Energy Regulatory Commission, Regulating Independent Power Producers, pp. 9-23, and the references cited there; and Department of Energy, Energy Security, pp. 154-60. 
ing in some parts of the country, however, so that the need to fix the system has become more urgent. ${ }^{55}$ While no intellectual consensus existed to provide a natural framework for regulatory and structural reforms, experience with Title II of PURPA, passed in late 1978 but not really implemented until the early 1980 s, has turned out to have provided both a positive and normative framework for some potential solutions.

\section{The Influence of PURPA}

In November 1978 Congress enacted the Public Utility Regulatory Policy Act, one of several pieces of energy legislation promoted by the Carter administration to deal with the energy crises. Two parts of PURPA are of particular importance to electric utilities. The first (Title I) addresses the regulation of retail electricity rates and load management services. It directs the states to consider alternatives to traditional ratemaking methods, including time-of-day rates, interruptible rates, lifeline rates, and the application of marginal cost-pricing principles. The states are under no federal obligation to do more than consider and evaluate the alternatives, although many have implemented reforms along these lines. ${ }^{56}$ It is fair to say, however, that the law's requirement that states "consider and determine" whether innovations would be desirable had little effect on decisions to adopt new rate structure principles (this section of PURPA is of no current policy importance).

The second section relevant to electric utilities (Title II) required them to purchase power from and provide backup services at nondiscriminatory rates to companies that install cogeneration equipment and certain small power-production facilities that make use of renewable energy sources and a variety of waste fuels, including garbage ${ }^{57}$ These cogen-

55. John McCaughey, "Unprecedentedly Low Electric Reserve Margins Ahead, Warns U.S. CEA," Energy Daily, September 7, 1988, p. 4; "Nationwide Peak Up 6.2\% from 1987, Tripling What Industry Predicted,' Electric Utility Week, October 17, 1988, p. 1; and "NEPOOL Capacity Margin Worsening Despite More Small Power Development," Cogeneration Report, April 22, 1988, p. 18.

56. Hethie Parmesano, William Bridgman, and Virginia Perry-Failor, "The Role and Nature of Marginal and Avoided Costs in Ratemaking: A Survey," National Economic Research Associates, November 1987; and Electric Power Research Institute, Innovative Rate Design Survey: 1986, EPRI EM-5705 (March 1988).

57. Paul L. Joskow and Donald R. Jones, "The Simple Economics of Industrial Cogeneration," Energy Journal, vol. 4 (January 1983), pp. 1-22. The small production 
eration and small power-production facilities that qualify under PURPA are referred to collectively as "qualifying facilities," or QFs. The new law directed FERC to issue rules defining the criteria independent suppliers had to meet to be QFs and specifying the methods to be used to determine the rates at which utilities would be obligated to purchase power from them and provide the backup and supplemental services. The only specific guidance in the statute, aside from the boilerplate provisions for just, reasonable, and nondiscriminatory rates, was that utilities could not be required to purchase at rates that exceed the "incremental cost to the utility of alternative electric energy." 58

In 1980 FERC specified how the relevant prices were to be determined (18 CFR 252). The agency established general ratemaking principles in its rules, but delegated their implementation to the state regulatory commissions. The general principle was that the price a utility is obligated to pay a QF should reflect the costs that the utility avoids (the "avoidedcost principle") by purchasing from an independent supplier compared with what the cost would have been if supplies had been made from the best alternative available. ${ }^{59}$ Thus utilities must purchase from QFs at rates equal to some estimate of their avoided costs, and QFs are not themselves subject to price, profit, or cost-of-service regulation. QFs can seek to obtain a price that reflects the market value for their electricity as specified in bilateral contracts with utilities. Given price and nonprice provisions specified in the contracts, a QF's financial performance

facilities were not to exceed $80 \mathrm{MW}$ for garbage burners and $30 \mathrm{MW}$ for other qualifying fuels. The size of qualifying cogenerators is unrestricted, and several such facilities exceed $300 \mathrm{MW}$.

58. Public Utility Regulatory Policy Act of 1978, Sec. 210(d); Department of Energy, Emerging Policy Issues in PURPA Implementation, DOE/PE-70404-H1 (March 1986), chap. 5 .

59. 18 CFR 292.101(a)(6). There has been ongoing controversy about whether the statute and the rule establish avoided cost at a ceiling, a floor, or the exact amount utilities must pay. FERC's initial rules were challenged because they appeared to require that utilities pay prices equal to their avoided costs. In American Paper Institute v. AEP, 461 U.S. 402 (1983), the Supreme Court held that FERC had the authority to require payments up to the buying utility's avoided cost. However, the original rules clearly anticipate that large QFs and utilities would negotiate individual contracts with the avoided cost rule available as leverage to appeal to the state regulatory agency if a mutually satisfactory contract could not be negotiated. FERC recently ruled that states cannot require utilities to pay more than avoided cost (Orange and Rockland Utilities FERC (1988)). 
depends entirely on its ability to control costs and deliver electricity. FERC largely left it to the states to specify how they would implement these principles.

As with any statute, the intent of Congress embodied in PURPA is difficult to determine. The statute and the legislative history refer to energy conservation, efficient use of electric facilities, reduced reliance on imported fuels, and equitable rates for consumers. ${ }^{60} \mathrm{It}$ is fairly clear that the statute does not reflect a broad intention to promote competition in wholesale generation markets, to encourage vertical deintegration of the electric utility industry, or anything nearly so exciting. But PURPA has provided the first significant opportunity for entrepreneurial independent suppliers of generation unencumbered by cost-of-service regulation to enter the market and provide an alternative to utility-owned generation.

\section{Supply-Side Responses to PURPA}

After five years of meaningful experience with PURPA, it may be useful to examine the law's effects on electricity supplied by nonutility generators (NUGs). ${ }^{61}$ Table 4 shows the capacity and MWh of generation associated with operating NUGs from 1966 to 1986, the latest year for which comprehensive data are available. These figures include all kinds of nonutility generation, including cogenerators and small power producers that fall under PURPA, as well as older cogenerators and conventional privately owned generating plants in operation before the law was passed. The aggregate U.S. numbers show that NUG capacity slowly declined until 1983 and then began to increase rapidly. The fraction of U.S. generating capacity available from NUGs declined significantly until 1983 and has increased slightly since then. By 1986 NUGs still provided a much smaller proportion of total U.S. generating capacity than they did in 1966, however. The pattern is similar for generation.

The figures in table 4 mask three conflicting trends. During these years a significant amount of pre-PURPA conventional industrial gen-

60. Conference Report on H.R. 4018, Public Utility Regulatory Policy Act of 1978, H. Rept. 1750, 95 Cong. 2 sess. (Government Printing Office, 1978).

61. Although PURPA was passed in late 1978, FERC did not issue regulations until 1980. Uncertainty over the key pricing provisions contained in these regulations was not resolved until 1983 in American Paper Institute v. AEP. 
Table 4. Nonutility Electricity Generation, 1966-86

\begin{tabular}{lcccr}
\hline Year & $\begin{array}{c}\text { Capacity } \\
(M W)^{\mathrm{a}}\end{array}$ & $\begin{array}{c}\text { Percent of } \\
\text { total U.S. } \\
\text { capacity }\end{array}$ & $\begin{array}{c}\text { Generation } \\
(M W h)\end{array}$ & $\begin{array}{r}\text { Sales to } \\
\text { utilities } \\
(M W h)\end{array}$ \\
\hline 1966 & 18,973 & 7.11 & 105,094 & 2,837 \\
1967 & 18,933 & 6.57 & 102,935 & 5,079 \\
1968 & 19,123 & 6.17 & 106,586 & 3,560 \\
1969 & 19,257 & 5.79 & 110,575 & 5,372 \\
1970 & 19,237 & 5.34 & 108,162 & 5,722 \\
1971 & 19,297 & 4.97 & 103,239 & 6,744 \\
1972 & 18,768 & 4.50 & 104,508 & 6,267 \\
1973 & 19,377 & 4.22 & 102,529 & 6,768 \\
1974 & 19,351 & 3.91 & 101,572 & 6,617 \\
1975 & 19,177 & 3.63 & 85,362 & 6,022 \\
1976 & 19,113 & 3.47 & 87,084 & 4,678 \\
1977 & 19,245 & 3.32 & 87,575 & 4,032 \\
1978 & 19,391 & 3.24 & 78,967 & 6,670 \\
1979 & 17,436 & 2.83 & 71,375 & 6,034 \\
1980 & 17,323 & 2.75 & 67,945 & 7,576 \\
1981 & 17,142 & 2.63 & 64,446 & 8,401 \\
1982 & 16,938 & 2.54 & 61,076 & 12,004 \\
1983 & 16,765 & 2.48 & 57,678 & 15,649 \\
1984 & 17,371 & 2.52 & 71,520 & 19,395 \\
1985 & 22,920 & 3.22 & 94,925 & 28,300 \\
1986 & 25,321 & 3.45 & 112,008 & 40,719 \\
\hline
\end{tabular}

Sources: Edison Electric Institute, Statistical Yearbook of the Electric Utility Industry, 1986 (Washington, 1987), pp. $7,15,16$. Data are from comprehensive EEI surveys: the federal government stopped collecting systematic data on NUGs after 1978.

a. 1989 capacity may be $32,000 \mathrm{MW}$.

erating capacity that provided some or all of the electrical needs of certain types of large industrial users was retired. This appears to have been especially true with regard to private power plants in the primary metals (iron and steel), mining, and transportation industries. ${ }^{62}$ Table 5 breaks down NUG capacity for 1979 and 1986 by type of supply source, along with retirements and additions in each category. About 40 percent of the capacity operating in 1979 had been retired seven years later, most of it associated with conventional industrial generators (included in “'Other industrial plants"). Approximately 15,000 MW of NUG capacity

62. For example, in 1981 the electricity generated by the primary metals industries was half what it had been in 1971. Total electricity used in primary metals in 1986 was only 20 percent of what it had been in 1971. See Bureau of the Census, Census of Manufactures and Annual Survey of Manufactures (Department of Commerce, various years). 
Table 5. Nonutility Electrical Generating Capacity Additions and Retirements, by Source, 1979-86

Megawatts

\begin{tabular}{lcccc}
\hline & & \multicolumn{3}{c}{ Source } \\
\cline { 3 - 5 } \multicolumn{1}{c}{ Activity } & Total & Cogeneration & $\begin{array}{c}\text { Small-power } \\
\text { production }\end{array}$ & $\begin{array}{c}\text { Other } \\
\text { industrial } \\
\text { plants }\end{array}$ \\
\hline Capacity, 1979 & 17,878 & 10,538 & 730 & 6,610 \\
Apparent retirements, 1979-86 & $7,255^{\mathrm{a}}$ & 2,184 & 46 & 5,025 \\
Net pre-PURPA capacity, 1986 & $10,624^{\mathrm{a}}$ & 8,354 & 684 & 1,585 \\
Post-PURPA additions, 1979-86 & $14,697^{\mathrm{a}}$ & 10,093 & 4,270 & 334 \\
Capacity, 1986 & 25,321 & 18,448 & 4,953 & 1,920 \\
\hline
\end{tabular}

Source: Edison Electric Institute, 1986 Capacity and Generation of Non-Utility Sources of Energy (Washington, July 1988), pp. 13-14.

a. Assumes capacity not identified is post-PURPA.

was added, almost all of which falls into the categories of cogeneration or small power production that would qualify under PURPA. Finally, although NUG capacity represents a very small fraction of current utility generation, it represents a much larger fraction of expected additions to domestic generating capacity. Projections are of course uncertain, but if one ignores the nuclear plants still under construction or awaiting licensing, projected capacity from cogeneration and small power production accounts for a third to a half of anticipated requirements over the next five to ten years. ${ }^{63}$

It is also useful to examine the relationship between nonutility generators and their local utilities. Before PURPA much of the NUG capacity was used exclusively to meet all or part of the electricity requirements of the industrial user owning that capacity. As I have already discussed, by and large NUGs supplied power for their own use, reducing demand on the utility, but did not produce additional power for sale to utilities. The new law gave NUGs the opportunity to sell all their production to their local utilities at the utility's marginal supply cost. Even though rising retail rates have probably increased incentives for cogenerators to use internal production to "back out" utility purchases

63. See "Summary of Market Development Projections of Fuel-Fired Projects,' RCG/ Hagler, Bailly Cogeneration and Small Power Data Base, as reported in Cogeneration Report, April 22, 1988, p. 13. The aggregate figures also mask wide regional differences in NUG capacity and generation. 
rather than sell their output, the proportion sold has increased dramatically since PURPA was passed. Table 4 shows total NUG production and sales to utilities: in 1978 only 5 percent went to utilities; by 1986 the figure was 36 percent.

\section{Implementing the Avoided-Cost Principle}

The experience of the past several years makes it clear that significant supplies will be forthcoming from independent suppliers at some price. But are the states setting the right price when they implement the avoided-cost principle? The process that regulators choose for specifying the price and nonprice terms and conditions of contracts between utilities and suppliers largely determines whether the system promotes an economical, reliable supply of electricity. Prices that are too high encourage unnecessary costly QF capacity to be built and operated, which wastes resources and leads to higher rates. Prices that are too low discourage less costly QF supplies, which also leads to higher rates. Is this regulatory environment leading to the right prices and quantities?

It is useful to start by asking why we need special regulations to govern utility decisions vis-à-vis purchased power at all. Why not treat utility procurement of purchased power like procurement of any other input? There are at least three potential problems that may have required regulatory intervention to promote economical purchases by integrated distribution utilities from QFs or independent suppliers more generally:

-Regulated distributors may have had private incentives to own generating facilities rather than to purchase power from third parties even when buying was more economical. Because expenses for purchased power are more or less passed through automatically in retail rates, the regulatory process historically provided little profit incentive to rely on purchases from third parties to meet capacity needs; purchased power transactions were a wash. ${ }^{64}$ This may have led utilities to avoid purchasing from third party suppliers and may have discouraged selfgeneration.

64. To the extent that there is an Averch-Johnson effect, it is almost certainly revealed in the own-or-buy decision rather than through input utilization distortions, assuming an integrated firm. However, since vertical integration is ubiquitous around the world and preceded modern rate regulation in the United States, it is unlikely that the A-J effect explains the vertically integrated structure of the industry. 
- Since a commercial or industrial firm that wants to cogenerate is connected to only one utility, it has only one buyer. The local utility may therefore have classical monopsony power, pay prices below competitive market levels, and artificially restrict purchases in favor of internal production. ${ }^{65}$

- Before the early 1980 s, retail rates were generally lower than estimates of the long-run costs of supplying central station electricity. Retail rates thus provided the wrong signals to industrial customers considering whether to buy electricity from the utility or to generate it themselves.

The requirement that utilities purchase from $\mathrm{QFs}$ at a price reflecting the buyer's avoided cost appears to have been a response to these perceived problems. Assuming that appropriate purchase contracts can be fashioned from estimates of avoided cost, the principle will encourage QF supplies to be offered by developers and selected by utilities if and only if these supplies are less costly than alternatives.

The avoided-cost approach has both strengths and weaknesses, however. Its primary strength is conceptual. To minimize the costs of supplying electricity, utilities should be willing to purchase from third parties when, all else being equal, these parties can supply generation at a lower cost than the utility can supply from generating facilities it owns or would otherwise build. Furthermore, the optimal supply of third party production will be forthcoming if the price on the margin is equal to the utility's avoided cost evaluated at the point where supply and demand are in balance.

65. I find it hard to get terribly excited about inefficiencies arising from utility monopsony power per se. The primary efficiency concern associated with classical monopsony power, a subject that has received little theoretical, empirical, or public policy attention, is that purchases of the inputs over which the buyer has market power will be artificially restricted. This increases the social costs of producing output while reducing the buyer's private costs of production. The extent of the restriction depends on the input (purchased power) supply elasticity, the elasticity of the derived demand for purchased power, the ability of the buyer to price discriminate, and various regulatory rules and procedures, including the use of competitive bidding procedures. Restrictions on purchases of economical supplies of power resulting from buyer market power per se are likely to be small. Monopsony power concerns are even less important for independent power producers that are not cogenerators and are not tied to specific sites within a utility's service area or where independent suppliers can obtain wheeling service to gain access to multiple purchasers. The primary barriers to the development of an independent generating sector before 1978 were unattractive economics and regulatory disincentives and barriers. 
The primary weakness of the avoided-cost principle is the difficulty of putting it into practice. Early discussions often gave the impression that the utility's avoided cost is a single objective number that can be easily calculated. But it is very difficult to calculate accurately the true avoided cost associated with a particular contractual relationship except in those circumstances in which the utility simply agrees to compensate the supplier based on the short-run operating and shortage costs avoided at the time of supply, a spot pricing system reflecting supply and demand conditions in real time. However, in addition to "avoided energy cost at time-of-delivery rates,' FERC and state rules often require that utilities offer QF suppliers the opportunity to enter into long-term contracts in which the supplier is paid for capacity and energy delivered based on a predetermined set of prices and price adjustment formulas. These contracts vary widely in initial delivery dates, duration of supply commitments, fuels and technologies used, reliability characteristics, dispatchability, price determination formulas, and allocations of risk between buyer and seller.

Unfortunately, there simply is no single objective measure of a utility's true avoided cost that can be calculated and then applied to determine the proper prices that a utility should agree in advance to pay cogenerators pursuant to diverse long-term supply relationships. When avoided costs are estimated in advance of delivery, the best we can do even theoretically is to calculate some measure of a utility's expected avoided cost at the time a contract is executed, given a host of assumptions about future supply and demand conditions. Even a utility's expected avoided cost will vary with numerous other conditions of specific contracts and with alternative assumptions about future supply (utility and nonutility) and demand conditions over the term of the contract. Mechanical formulas can estimate avoided cost only imperfectly-in many cases very imperfectly. Neither FERC nor most state agencies initially understood the difficulties of implementing the principle through administrative determination of the terms of contracts between buyers and sellers. ${ }^{66}$

A very simple example will help to illustrate some of the basic problems. Assume that utilities can either build and operate their own

66. Actually, except for contracts with very small QFs, there is nothing in the statute or FERC's initial rules that requires state regulators to force utilities to specify a general "standard offer" contract based on which they must purchase from any and all willing suppliers. The original rules seem to anticipate that bilateral negotiation is preferable to administrative specification of generic contract terms. 
Figure 10. Prices and Quantities of Electricity Purchased from Small Power Generators Utility's avoided costs

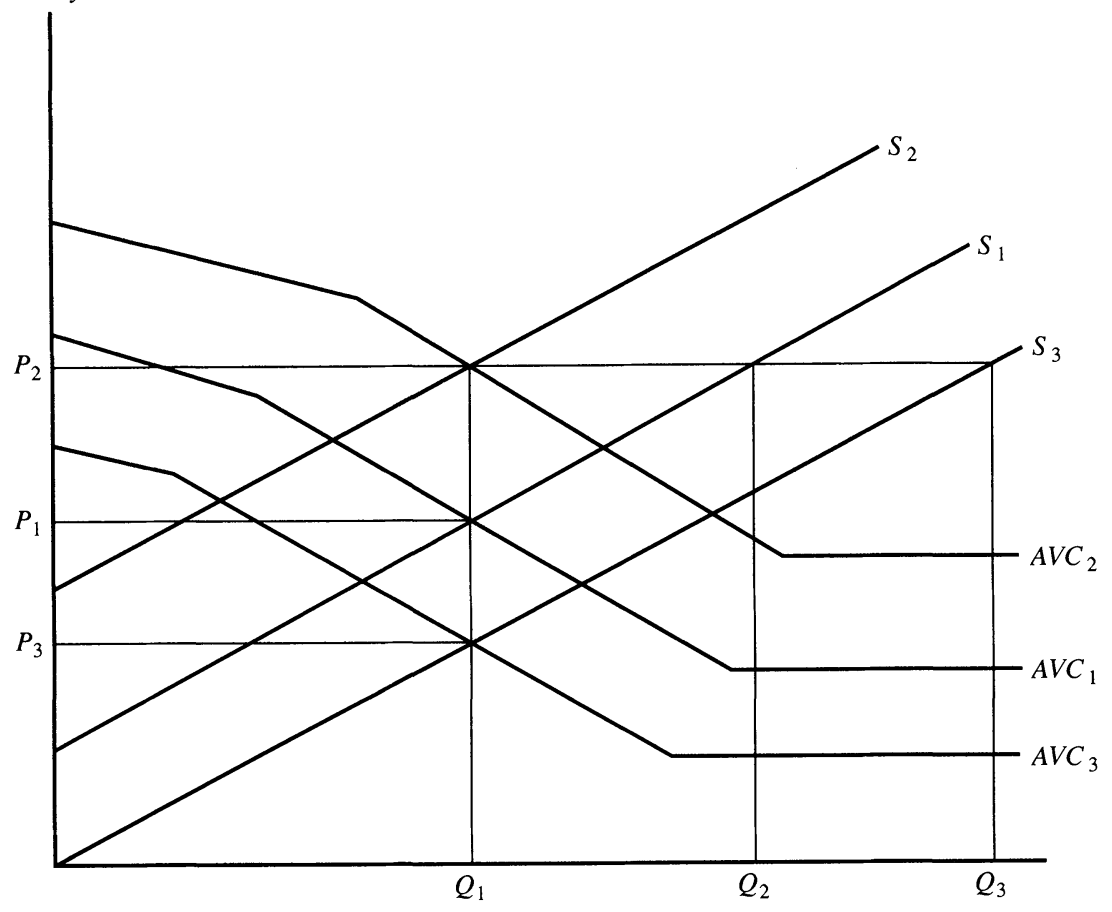

Purchases from $Q F s$

generating capacity or purchase power from a heterogeneous group of suppliers to meet expected loads in a particular period in the future. If a utility meets all future needs with its own generating resources, one measure of its long-run avoided cost can be calculated by determining how much its average annual gross supply costs would be reduced if increased quantities of capacity were purchased instead of generated by its own plant. Such a calculation is reflected in the downward sloping function $A V C_{1}$ in figure 10 . This is a cost-minimizing utility's derived demand for third party supplies. The $A V C_{1}$ function has purposely been drawn to have a slope that varies with the amount of capacity acquired. Power purchased from third parties initially displaces capacity that the utility would otherwise build to meet expected electricity demand. As more QF capacity is purchased, additional utility capacity is no longer needed and the utility eventually experiences a growing surplus of generating capacity. The initial purchase of additional capacity has some 
value related to improved reliability and deferral of subsequent capacity additions, but at some point, additional capacity has no capacity value at all and only displaces the operation of existing utility generating capacity.

The first thing to note is that even if $A V C_{1}$ were known with certainty, it would generally be a function of the amount of third party supply acquired, not a single value. The second thing is that since the calculation typically must be made for a period that extends far into the future, there is great uncertainty about where $A V C_{1}$ actually lies. If, for example, fuel prices are higher than expected, the actual avoided costs could end up looking more like $A V C_{2}$. If demand growth is slower and fuel costs lower than expected, the actual avoided-cost function could end up looking like $A V C_{3}$. The best that we can do is come up with some expected value for the avoided-cost function, recognizing that it is uncertain.

Even if we knew with certainty that $A V C_{1}$ is the true avoided-cost function, determining administratively the price that utilities are required to pay requires knowing what the supply of third party generation will be at various prices, since avoided cost is not a single-valued function (while this observation may seem obvious, it has eluded many regulators). A hypothetical QF supply schedule is depicted as $S_{1}$ in figure 10 . Of course this supply schedule is known only with considerable uncertainty as well. It could be higher $\left(S_{2}\right)$ or lower $\left(S_{3}\right)$. If we knew with certainty that the relevant avoided-cost and QF supply functions were $A V C_{1}$ and $S_{1}$, then the optimal price would be $P_{1}$. If a utility offered to buy at this price, a competitive QF supply response would be $Q_{1}$. However, if there are two other possible states of nature $\left(A V C_{2}\right.$ and $S_{2}$ and $A V C_{3}$ and $S_{3}$ ), the optimal prices could be either $P_{2}$ or $P_{3}$. As I have drawn figure 10 , the optimal quantity is always $Q_{1}$, however.

Assume that the regulator guesses wrong. He sets $P_{2}$ as the offer price assuming that $A V C_{2}$ is the relevant avoided-cost function and $S_{2}$ the relevant QF supply function. It turns out, however, that $S_{1}$ or $S_{3}$ is the actual supply function and $A V C_{1}$ or $A V C_{3}$, the actual avoided-cost function. By setting $P_{2}$, a competitive QF supply response is $Q_{2}$ or $Q_{3}$, much more than the optimal quantity that should be supplied. Alternatively, assume that the regulator sets $P_{3}$, assuming that $A V C_{3}$ and $S_{3}$ are the true avoided cost and QF supply functions, but the actual state of nature is $A V C_{2}$ and $S_{2}$. The competitive supply response is now zero output rather than $Q_{1}$. Clearly, setting fixed prices administratively ex 
ante and allowing the competitive QF supply sector to respond to them can lead to very costly mistakes when avoided costs and QF supply responses are uncertain.

To complicate matters further, long-term supply contracts with QFs are generally negotiated at least five years before first delivery of power and specify a delivery and payment schedule for periods of ten to twenty years thereafter. At any particular time, the contracts negotiated generally include suppliers who promise to begin delivery in several different years. Contracts for capacity needed beyond five years into the future may be negotiated at various times. While contracts could specify a single fixed price, there are good reasons to believe that this would be inefficient. Optimal long-term supply contracts will generally have fairly complex price and nonprice provisions to properly align incentives to perform, reflect differences in the value of contracts with different supply attributes, and reflect the allocation of risks between buyers and sellers. Thus the regulators' task involves simulating what a diverse set of optimal supply contracts would look like if there were a competitive market for third party supplies. This is a formidable undertaking. Indeed, to simulate the contracts accurately, regulators would have to go beyond the frontier of current knowledge regarding the economics of long-term contractual relationships.

There was initially very little sensitivity to the problems associated with regulatory simulation of the right equilibrium price and nonprice contractual provisions. Several states used fairly mechanical estimation approaches to come up with standard-offer contracts with fixed terms and conditions available to all QF suppliers and have made costly mistakes. ${ }^{67}$ Probably the clearest example of the dangers of relying on administrative procedures to simulate the terms and conditions of generally available, long-term fixed-price standard-offer contracts for

67. Department of Energy, Emerging Issues in PURPA Implementation, table 11; and Federal Energy Regulatory Commission, Notice of Proposed Rulemaking Re Administrative Determination of Full Avoided Costs, Docket no. RM88-6-000 (March 16, 1988), p. 11, note 24 . The problem was not just that regulators made mistakes but that the enthusiasm of some to promote cogeneration and small power production led them to set rates that were far above reasonable estimates of avoided costs (chap. 6). On the other hand, many state commissions, recognizing that plenty of generating capacity was available, initially mandated only that utilities pay avoided energy costs at the time of delivery, leaving longer-term contracts to negotiation (p. 12, note 26). This was the initial approach taken by Massachusetts, for example. 
QFs is California's experience. Contracts in California specified payments that were too high, the payments were not adjusted quickly to reflect changing fuel prices, and the excessive payment attracted too much supply. The costs of these contracts, or the payments utilities have been making to buy them out or defer them, will lead to higher electricity prices for other retail customers. ${ }^{68}$ Other states-Texas, Maine, New York, Connecticut-faced similar problems, although they generally found ways to allocate the excess supplies. The experience with price regulation through standard-offer contracts has shown how to integrate third party suppliers into the system inefficiently. It has increased or will unnecessarily increase electricity costs and prices.

\section{Competitive Bidding and Negotiation Systems}

If all one had to go on was the early experience with PURPA and regulator-determined terms and conditions of standard-offer contracts, the effort to develop an independent power sector would not at first blush have much to recommend it. Happily, California's procedure is not the only way to structure an efficient procurement system. One alternative is to set target quantities (for example $Q_{1}$ in figure 10) and require utilities to solicit competing bids to supply these quantities, choosing the most economical mix of bids submitted. ${ }^{69}$ The regulator sets the quantities and the market sets the prices.

Another approach would be to go to the heart of the matter by removing the primary regulatory distortions that may lead utilities to fail to enter into economical power supply contracts with third parties. Utilities would then simply be expected to negotiate with competing QF and other wholesale power suppliers, as they do with suppliers of other inputs such as coal. ${ }^{70}$ Since at least some internal production could be

68. Department of Energy, Emerging Issues in PURPA Implementation, pp. 635-42; and Federal Energy Regulatory Commission, Notice of Proposed Rulemaking of Full Avoided Costs, p. 11, note 24.

69. The analogy to the price versus quantities literature should be obvious. See Martin L. Weitzman, “Prices vs. Quantities,' Review of Economic Studies, vol. 41 (October 1974), pp. 477-91.

70. This appears to be how FERC originally anticipated contracts between utilities and larger QFs would be consummated. The 1980 rules do not entitle large QFs to standardoffer contracts. Regulations Implementing Section 210 of PURPA, 18 CFR 292. 
more efficient than power supplied by third parties, utilities could also be permitted to own new generating capacity themselves, but only if they could convince regulators that more economical supplies were not available. Information from contracts signed with third parties by utilities in a given region provides a natural yardstick against which to evaluate utility construction projects. I will refer to this approach as the competitive negotiation-yardstick approach.

There are good reasons to believe that a competitive bidding or competitive negotiation-yardstick approach (quantity regulation) will work much better than standard-offer contracts (price regulation). It is often much easier for regulators to estimate how much capacity a utility is likely to need over a reasonable time than it is for them to specify the proper price and nonprice terms and conditions of standard-offer contracts. Figure 10 makes this point starkly. The optimal price could be $P_{1}, P_{2}$, or $P_{3}$, depending on which of three uncertain states of nature is realized. The optimal quantity, $Q_{1}$, is invariant to the state of nature, however. Setting the wrong price can lead to quantities that are far from optimal. But if approximately the right quantity can be set, it makes much more sense to target quantities and use a bidding or negotiation system to determine the proper contract elements. If quantities are specified, the risks of buying too much or too little capacity and paying too much for whatever capacity is acquired are minimized. These two approaches also fit in naturally with utilities' planning procedures.

The difference between competitive bidding and competitive negotiation turns primarily on how much flexibility the utility is given in bilateral negotiations and how much must be specified through rigid "self-scoring" contract-evaluation mechanisms subject to detailed regulatory scrutiny. (It probably makes sense to think of there being a continuum between a highly structured self-scoring system and a competitive negotiation system in which the utility retains considerable flexibility to evaluate individual contracts and various combinations of contracts and internal production.) If regulatory incentives toward or against owning generating capacity can be ameliorated or a utility agrees to buy all additional generating capacity in the market, flexible competitive negotiations are clearly preferable. Because potential suppliers have diverse characteristics of economic consequence, it makes sense to allow the utility rather than the regulator to specify weights for evaluating contract terms and conditions, subject to regulatory review 
to guard against self-dealing, as well as the planning assumptions regarding fuel prices, general inflation, and interest rates. Suppliers are then free to structure their bids to reflect the weights announced by the utility, the economic and technical attributes of a particular supply technology, and the supplier's own risk preferences. The utility, in turn, is then free to meet its needs with the best mix of supply offers made. Competition between third party suppliers helps ensure that the utility does not pay too much for third party supplies. If the utility does not get enough bids to meet its capacity needs or determines that it is more economical to build capacity itself to satisfy some or all of its needs as well, the offers made to it through a competitive solicitation process provide a natural benchmark or yardstick against which this decision can be evaluated and, in theory, upon which compensation arrangements for utility-owned generation can be made. In either case the regulatory objective is to stimulate a competitive market for third party supplies of generation and to introduce regulatory rules and incentives that lead a utility to choose the best mix of supply options.

Only further experience with alternative approaches to generation proeurement can give us firm empirical evidence regarding the strengths and weaknesses of various combinations of structured bidding programs and more flexible negotiation programs. However, it is already becoming clear that rigid, self-scoring competitive bidding systems that leave little room for bilateral negotiation work poorly compared with more flexible competitive negotiation systems.

\section{Bidding and Negotiation Systems in Practice}

A growing number of states have permitted or required utilities to use a competitive bidding or negotiation system to determine the conditions governing purchases from facilities qualifying under PURPA.${ }^{71}$ In some

71. Houston Lighting and Power was the first utility to propose using a competitive bidding system. The Texas Commission did not approve, in part because it was uncertain whether a bidding system was legal under PURPA, but it allowed the company to set quantities and then negotiate the best deals they could with competing suppliers. Central Maine Power, faced with a similar problem, was permitted to implement the first competitive bidding system in the country. Department of Energy, Emerging Issues in PURPA Implementation, pp. 5.44-5.54. 
Table 6. Selected Competitive Bidding and Negotiation Programs for Electric Utilities Megawatts

\begin{tabular}{lcc}
\hline \multicolumn{1}{c}{ Utility } & Capacity & $\begin{array}{c}\text { Total } \\
\text { capacity } \\
\text { of bids } \\
\text { received }\end{array}$ \\
\hline Central Maine Power (1987 solicitation) & 200 & 1,444 \\
Sierra Pacific (Nevada) & 125 & 2,800 \\
New England Power & 200 & 4,729 \\
Virginia Power & 1,750 & 14,000 \\
Eastern Edison (Massachusetts) & 30 & 180 \\
Boston Edison (first) $\quad 200$ & 2,053 \\
Green Mountain Power (Vermont) & 400 & (in progress) \\
Jersey Central P\&L & 114 & 806 \\
Delmarva P\&L (Delaware) & 180 & (in progress) \\
Orange and Rockland Utilities & 200 & (in progress) \\
Long Island Lighting & 100 & (in progress) \\
\hline
\end{tabular}

Source: Electric Utility Week and Cogeneration Report, various issues.

cases competitive bidding or negotiation systems have been extended to encompass all supply sources, not just QFs. ${ }^{72}$ Table 6 lists some utilities that have introduced such systems. In general, these programs involve utilities issuing requests for proposals for specified quantities of QF capacity (or sometimes capacity from non-QF wholesale suppliers, or IPPs). In some cases the request specifies the proposed evaluation criteria in sufficient detail that responses can be used directly to rank and select winners (self-scoring RFPs), subject only to limited negotiation of the detailed provisions of a final contract. In other cases the RFP is used as a screening device to select a few suppliers that utilities then negotiate with to arrive at final selections and specific contracts.

So far all utilities that have introduced competitive bidding and negotiation systems have found abundant supplies offered in response to RFPs and have generally been able to fill some or all of their capacity

72. There is also a growing but unfortunate trend to allow conservation options to bid against new supply sources, which reflects a profound confusion between supply, demand, and consumer and producer behavior. Paul L. Joskow, Testimony before the Subcommittee on Energy and Power of the House Committee on Energy and Commerce, March 31, 1988, in FERC: Electricity Demand Side Bidding, 100t-197 (1989); and "The Role of Conservation Programs in the Bidding NOPR," memorandum from FERC Commissioner Charles Stalon, March 4, 1988. 
needs with QF and IPP contracts that appear to have very attractive terms. The winning bidders are often major companies with substantial experience designing, building, or operating generating plants. ${ }^{73}$

It has also become clear that QF suppliers are willing to build facilities if and only if utilities' purchases are supported by long-term purchase contracts that obligate the utility to purchase power over a long period of time at prices specified in advance in the contract. This reliance on long-term contracts as an alternative to vertical integration is not surprising. Investments in generating facilities have important relationship-specific attributes of the type discussed in the literature on the theory of the firm and contracts. ${ }^{74}$ Independent generating facilities have usually been built to sell power to a single utility or, in a few cases, to two or three proximate utilities. In the latter cases the independent supplier must rely on the utility that serves the area in which the plant is located to provide a contractual transmission path (wheeling) to the other buyers. Once these investments are sunk, suppliers are not likely to be in a particularly attractive bargaining position, and investors must be concerned about the hazards of customers' opportunistic behavior. Even in areas such as New England, where wheeling service has generally been made available to independent power suppliers if they want it to get to their preferred customers, long-term contracts are the norm. While regulation can in principle mitigate contractual hazards, suppliers generally recognize that regulatory protections are necessarily limited.

The reliance on long-term contracts leads to several difficult issues. Some mechanism must be found for setting a price level and structure for each contract that will encourage suppliers to make efficient invest-

73. "At Least 3 Utility Independent Power Units Win in Va. Power Solicitation," Electric Utility Week, November 28, 1988, p. 12; and "Utility Units Tripled Investments in Independent Power in Past Year," Electric Utility Week, December 5, 1988, p. 17.

74. Benjamin Klein, Robert G. Crawford, and Armen A. Alchian, "Vertical Integration, Appropriable Rents and the Competitive Contracting Process," Journal of Law and Economics, vol. 21 (October 1978), pp. 297-3 $\rightarrow$ Paul L. Joskow, "Vertical Integration and Long-Term Contracts: The Case of Coal Burning Electric Generating Plants," Journal of Law, Economics and Organization, vol. 1 (Spring 1985), pp. 33-80; Joskow, "Contract Duration and Relationship-Specific Investments," American Economic Review, vol. 77 (March 1987), pp. 165-85; and Oliver E. Williamson, "Credible Commitments: Using Hostages to Support Exchange,'” American Economic Review, vol. 73 (September 1983), pp. 519-40. 
ments, encourage efficient production decisions once facilities have been built, and protect consumers from paying more than necessary. This is not an easy task. Independent power supplies come from various technologies with different capital, fuel, reliability, and dispatchability characteristics and they rely on different financing arrangements. The price structure chosen will affect sellers' incentives to perform when uncertain contingencies arise, the allocation of risks between buyer and seller, and the economical integration of individual generating facilities into the larger electric power system. The competitive market value, or avoided cost, of different supply arrangements will vary, and it is difficult to quantify these variations precisely.

These contracting complexities suggest that regulators should try to allow the parties to negotiate freely when they are reasonably confident that regulatory conditions will not create a bias against third party suppliers, that cost recovery mechanisms and associated incentives will encourage the buyer to put together an efficient supply mix, and that regulatory and competitive conditions are such that monopsony power is not a serious source of distortion. Efforts to create a regulatory environment that provides incentives for utilities to evaluate all supply options on an equal footing without regard to ownership per se make it possible to maximize the flexibility utilities have to negotiate bilateral contracts with diverse suppliers and to minimize direct regulatory intervention in the structure of the contracts negotiated between utilities and third party suppliers, an area where regulation is likely to be especially imperfect.

The recent experience in Massachusetts is instructive. Despite very tight supplies and aside from some peaking capacity and repowering of old generating facilities, utilities there and in New England in general have no plans to build major power plants. ${ }^{75}$ The utilities seem to believe that building generating projects under cost-of-service regulation presents more risks than potential rewards. They are therefore committed to looking first to the wholesale market (including Canada) for additional generating capacity.

In 1987 Massachusetts utilities began implementing new regulations for purchases from QFs. ${ }^{76}$ They now operate under two parallel systems.

75. North American Electric Reliability Council, 1988 Electricity Supply and Demand, app. D.

76. Massachusetts Department of Public Utilities, D.P.U. 84-276-B (October 1986). 


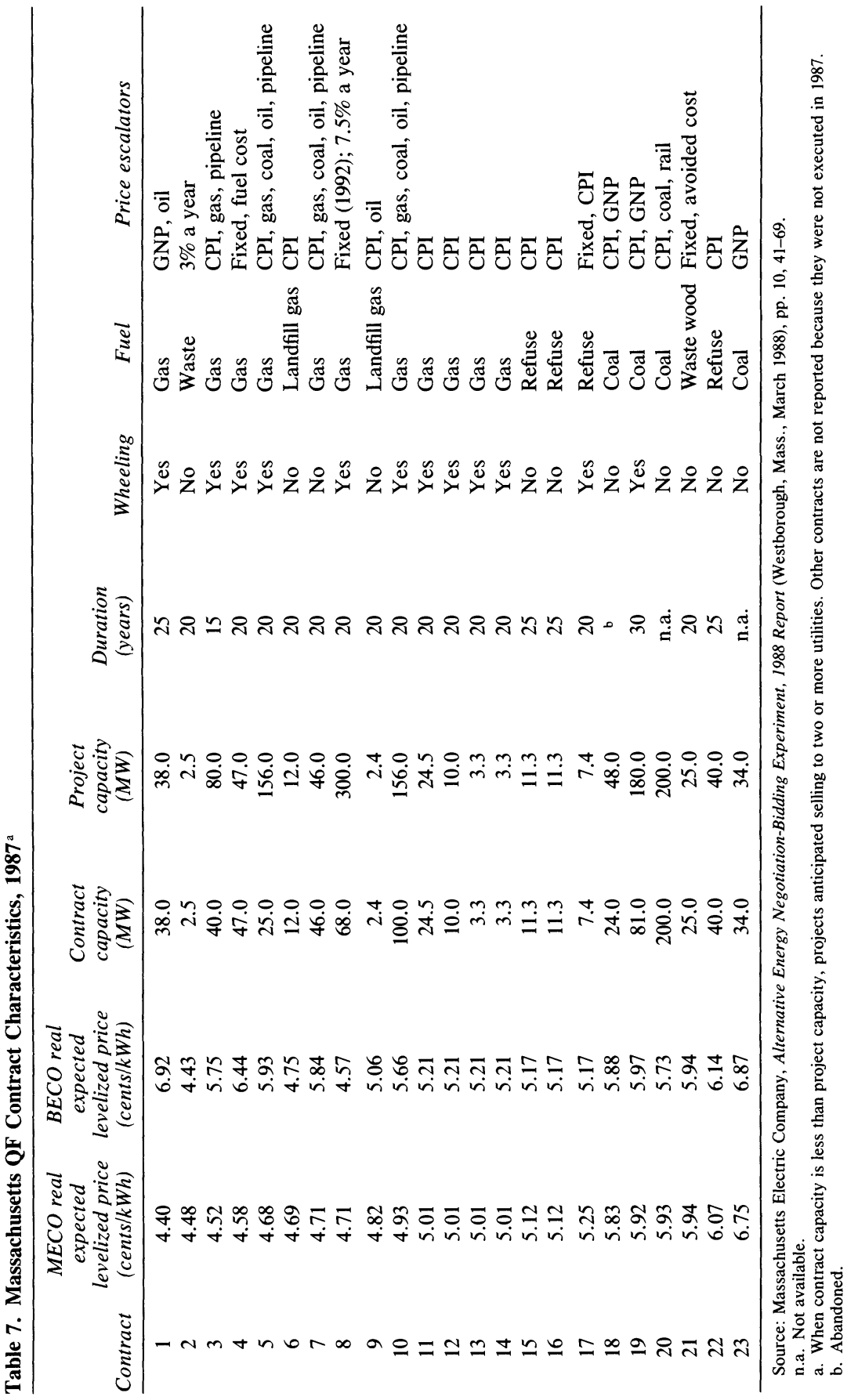


All utilities in the state, except for the largest, are required to use competitive bidding for QF capacity using regulator-approved, selfscoring competitive bidding that leaves little room for negotiation after bids are received. They must seek bids for a specified amount of new capacity at least once each year. They are also required to file an RFP and standard contract with the Department of Public Utilities that specifies the buyer's projected avoided costs each year for the next twenty years, the underlying fuel price, inflation and interest rate assumptions, and the weighting criteria for evaluating the bids. The utilities have considerable freedom to define weighting factors for a large number of supplier and contractual attributes, subject to ultimate approval by the department. Once the RFP is approved, utilities seek bids, rank them, select an award group, and negotiate final contracts. Opportunities to negotiate on price-related terms and conditions of the final contracts are severely limited. Utilities can continue to negotiate contracts with QFs outside the bidding process, but capacity purchased in this way does not count against the amount of capacity they are required to put up for bids.

The largest utility in the state, Massachusetts Electric (MECO), sought an experimental exemption from the bidding rules, proposing that it be allowed to continue to purchase power from QFs using a negotiation system of its own choosing. The company supported its request by citing its good experience in negotiations with QFs, its commitment to purchasing from third parties when they offered the most attractive sources, its willingness to wheel out QF supplies to other utilities in New England so that sellers in its territory had competing buyers, and its view that self-scoring bidding systems with limited opportunities for negotiation would not work well. In return for the exemption MECO agreed to collect and evaluate data on contracts achieved through both bidding and negotiation for all utilities in the state and to survey QF developers' evaluations of the different systems.

The results for the first year of the Massachusetts experiment are now available. Table 7 shows the expected real levelized prices and the capacity offered for the twenty-three contracts reached through bidding or negotiation in 1987. Two sets of prices are listed. In each case the price indicated is the levelized real expected price over the life of the contract, given the escalation provisions in the contract. The first price series calculates these values using Boston Edison's (BECO) assump- 
tions about future fuel prices and interest rates. The second price series uses MECO's assumptions. The expected prices fall within a fairly narrow band. The mean prices for the contracts under the two sets of assumptions about future input price levels are 5.2 and 5.6 cents $/ \mathrm{kWh}$, respectively (median 5.01 and 5.73), with standard deviations of 0.61 and $0.64 .{ }^{77}$ Projects of a wide variety of sizes and fuels were chosen. However, the 5 with capacities of $100 \mathrm{MW}$ or more account for 70 percent of the capacity that will be supplied. This is consistent with national data. Of 2,449 NUG projects operating in 1987, the 58 with capacity greater than $100 \mathrm{MW}$ accounted for 40 percent of the total NUG capacity. ${ }^{78}$ Finally, it is clear that projects cannot be ranked independently of the underlying assumptions one makes about future fuel prices, interest rates, and so forth. For example the project with the lowest expected price under BECO's assumptions had the highest under MECO's. Similarly, the project with the third lowest price under MECO's assumptions had the ninth lowest under BECO's.

Table 7 also provides information about price-adjustment provisions in the contracts. Most have base price plus escalation adjustment provisions. The specific provisions vary significantly: some contracts index prices to changes in the CPI or the GNP deflator; others include various fuel price indexes (oil, gas, and coal) in the formulas. The adjustment provisions chosen by some sellers reflect provisions in their own fuel supply contracts. Only one of the contracts has anything like a market price adjustment provision. These provisions are consistent with buyer concerns that the contracts make it in the interest of the seller to continue to perform when economic conditions change. ${ }^{79}$

As Joskow and Schmalensee hypothesize, long-term contracts appear to be important in securing investments by new independent suppliers of generation service. ${ }^{80}$ However, the contracts are far different from the implicit contract associated with textbook cost-of-service regulation. These contracts are not pure cost-plus contracts: the sellers generally

77. There is significantly less variance in these prices than in those in comparable longterm coal contracts. Paul L. Joskow, "Price Adjustment in Long-Term Contracts: The Case of Coal,'” Journal of Law and Economics, vol. 31 (April 1988), pp. 47-83.

78. Edison Electric Institute, 1986 Capacity and Generation of Non-Utility Sources of Energy (Washington, July 1988), p. 32.

79. Joskow, "Price Adjustment in Long-Term Contracts."

80. Joskow and Schmalensee, Markets for Power, pp. 109-27. 
take on most of the risks associated with the construction costs of the project and the performance (availability) of the facilities, although larger, more capital-intensive projects may allocate more of the construction and operating risk to buyers in the future.

The Massachusetts experience also sheds some light on the relative costs and benefits of highly structured bidding systems and more flexible competitive negotiation systems. Utilities in Massachusetts have moved aggressively to meet pressing capacity needs almost exclusively with third party supplies. There is no evidence that utilities are trying to avoid buying from third parties so that they can build capacity themselves. If there is a bias, it probably cuts the other way. Buyers also appear to have had little difficulty in arranging for wheeling service: more than half the contracts signed by Massachusetts utilities in 1987 were accompanied by such arrangements. Thus suppliers tied to a specific site can still seek to sell their capacity to competing buyers and not just to the local utility, which diminishes any monopsony power the local utility might otherwise have, a deduction that is supported by statistical analysis showing no significant difference between expected real prices in bid and negotiated contracts after controlling for other contract characteristics. ${ }^{81}$ Thus there is no evidence here that a negotiation system allows utilities to exercise monopsony power, pay less, or buy less from QFs. Furthermore, an independent survey found that QF developers generally preferred the flexibility of negotiation to the rigidities of the bidding system, although they had numerous suggestions for improving both. ${ }^{82}$

At the very least, for a utility with attributes such as MECO's there appears to be little reason not to rely on flexible competitive negotiation. Furthermore, there are clear practical problems with rigid self-scoring competitive bidding systems, which may already be emerging in Massachusetts. Boston Edison, the company farthest along with a highly structured bidding system that has little room for bilateral negotiations, has run into problems with several of the projects selected through bidding. ${ }^{83}$

81. Massachusetts Electric Company, Alternative Energy Negotiation-Bidding Experiment, 1988 Report (Westborough, Mass., March 1988).

82. Temple, Barker, and Sloane, Inc., "Qualifying Facilities Survey: Results of Findings,"' December 1987.

83. “Edison Small Power Plans Dim,'” Boston Globe, December 11, 1988, p. 73. 


\section{The Impact of the PURPA Experience}

PURPA's likely long-term effects on the electric power industry cannot be measured solely by looking at how much QF capacity has been forthcoming or how much money utilities have saved or lost by increasing their reliance on independent suppliers. Whatever its original intent, and despite numerous implementation problems, PURPA has been a sort of experiment with partial deregulation of entry into generation supply stimulated by pricing arrangements that are not tied directly to the seller's accounting costs and that allocate substantial construction cost and operating performance risks to the seller. PURPA has shown that under the right conditions independent suppliers will provide economical supplies of electricity; utilities are not the only ones that can build and operate generating plants successfully. (It has also shown that under the wrong regulatory and economic conditions uneconomical supplies will be forthcoming.) While Title II of PURPA was passed primarily as an energy conservation initiative, it has opened the way for competitive entry into generation and the bulk power market. But why should the opportunities for unregulated suppliers of wholesale generating service to contract with distribution utilities be restricted to certain classes of technology or certain size categories specified by PURPA? Why not expand the opportunities buyers and sellers have to negotiate mutually satisfactory wholesale power supply contracts, unencumbered by entry restrictions or cost-of-service regulation, to any supplier of generating service willing to compete to supply electricity at wholesale to distribution utilities?

PURPA has created a new constituency of independent power suppliers who have been active in promoting state and federal policies that expand opportunities for independent power producers who do not meet PURPA's efficiency, fuel, and size restrictions to compete to supply generation to utilities at prices that reflect the competitive market value of the electricity rather than the supplier's accounting cost of service. At the same time, many utilities are receptive to increased reliance on third party supplies. Because of the financial pain resulting from economic conditions and regulatory decisions of the 1970s, many are reluctant to commit themselves to building major new generating facili- 
ties. ${ }^{84}$ They would like to shift more of the financial risk to third parties. As a result a large number have shown interest in encouraging competitive entry into the generation market to help them balance supply and demand in the 1990s. Other utilities see more open entry as a way to compete to supply generation to other distribution utilities outside of their traditional service territories and without traditional cost-of-service constraints.

Thus both potential buyers and sellers have become interested in nonPURPA generating facilities dedicated to the wholesale market and to sales under contract to traditionally integrated utilities. The $470 \mathrm{MW}$ Ocean State Power combined-cycle plant in Rhode Island that is now under construction and has received FERC approval for a novel sales contract, is an excellent example. Other facilities designed to burn gas or coal are on the drawing boards and looking for buyers willing to make contractual commitments to purchase power ${ }^{85}$ More and more large cogeneration projects are entering the market that are really small standalone generating plants which have contrived process steam loads to obtain QF status under PURPA. ${ }^{86}$ But for PURPA's technology, size, fuel, and thermal efficiency restrictions on qualification for competitive entry and waiver of cost-of-service regulation, these facilities would not be cogenerators. ${ }^{87}$ The developers would like the opportunity to compete with other supply sources without having to pay a "PURPA tax." In return they are willing to give up utilities' obligations to purchase arising directly from PURPA.

84. Federal Energy Regulatory Commission, Regulating Independent Power Producers, pp. 18-21; Department of Energy, Energy Security, pp. 154-60; and the references they cite.

85. "FERC Okays Ocean State Plant in R.I. Where Investors Will Bear Full Risk," Electric Utility Week, January 19, 1987, p. 1; Ocean State Power, 38 FERC 61,140 (1987) and 44 FERC 61,261 (1988); and "PG\&E, Bechtel Form Joint Venture for Independent Projects," Cogeneration Report, January 1, 1988, p. 12.

86. Federal Energy Regulatory Commission, Regulations Governing Independent Power Producers, p. 6.

87. PURPA has also had more indirect effects on the retail ratemaking process. Although distribution utilities provide retail service pursuant to de facto exclusive geographical franchises, they cannot keep customers from supplying electricity for themselves. The stand-alone cost of such self-generation is a natural upper bound on what a utility can charge, regardless of what its accounting costs happen to be. PURPA has helped to reduce the costs of self-generation by requiring utilities to provide nondiscrimi- 


\section{Evaluation of Current Trends}

Recent experience with the development of an independent generating sector has yielded varied results, some promising and some discouraging. If the price and regulatory conditions are right, third party suppliers will supply electricity to utilities under long-term contracts that allocate construction costs and operating risks to the sellers. Many sellers have been able to supply at a price lower than the purchasing utility's estimated costs for generating the power itself. Cogenerators in particular appear to have excellent availability records. ${ }^{88}$ The costs and benefits of encouraging more reliance on independent suppliers depend critically on the rules under which contracts are written. The standard-offer contract approach (price regulation) has been a failure. The highly structured competitive bidding approach is better, but may well prove unworkable for larger projects. Utilities that have been allowed to use more flexible competitive negotiation mechanisms appear to be achieving the greatest success. It is also clear that negotiating a contract is only one step toward a project's generating electricity. Many contracts have been terminated and have not led to completed power plants. Careful evaluation of proposed projects as well as cooperation between buyer and seller to make the project a reality is very important.

I am reasonably optimistic that current developments can help improve the allocation of resources associated with providing electricity by creating a competitive market for wholesale power supplies and

natory backup and supplemental service for cogeneration and to purchase excess production from the supplier at a rate reflecting the market value of the supplies. In industries where cogeneration is technically and economically feasible (pulp and paper, chemicals, food processing, oil refining, and others) the threat of self-generation has increasingly forced utilities to offer rates, sometimes called incentive or cogeneration deferral rates, below the traditional accounting cost of service. Cogeneration deferral rates have now become routine. While the discount rate is below the average accounting cost of service, it is above the utilities' marginal or avoided cost associated with serving the affected customers. For example, see Wiliam Pollard and Vivian W. Davis, "New Rates Designed to Encourage Economic Development and Load Retention," NRRI Quarterly Bulletin, vol. 8 (April 1987), pp. 227-40; “'Florida Okays Second Cogeneration Deferral Agreement for Gulf Power," Electric Utility Week, November 18, 1988; and "PG\&E, Socal Ed File Cogeneration Deferral Contracts with California PUC,' Electric Utility Week, November $18,1988$.

88. "Texas Cogeneration Projects Said to Have 95.7\% Availability Factor," Electric Utility Week, December 12, 1988, p. 17. 
providing incentives to utilities to provide for their generating needs through purchase rather than ownership when purchase is more economical. While the potential benefits of these changes are clear, some significant uncertainties about their long-term consequences must be recognized and factored into public policies. Several regulatory barriers could also lead to serious problems.

\section{System Reliability}

Perhaps the primary issue that has not been addressed adequately is whether increased reliance on third party generation will eventually create problems of coordination and reliability that are handled more efficiently when generation, transmission, and distribution are under common ownership and where cooperation rather than competition is the norm. ${ }^{89}$ Although such problems have not yet become serious, the quantity of independent generating capacity is still small. Independent generators have been able to depend on an existing integrated backbone generation and transmission system developed in the context of an industry structure that did not comprise independent power suppliers. Most projects have also operated for only a short time. The efficiency of the existing system relies extensively on the economical dispatch of multiple generating units under common ownership, real-time coordination of interconnected facilities under separate ownership through power-pooling arrangements and bilateral agreements, and extensive cooperation among interconnected utilities to maintain reliability. How well will these arrangements function with many more independent suppliers? What changes will have to be made to make such an interconnected electricity system work efficiently? What kinds of contractual rigidities and imperfections will emerge as economic conditions change?

There are good economic reasons to believe that uncertainty, relationship-specific investment, asymmetric information, the complexities of coordinating an integrated electric power system reliably and economically, and incomplete contracting may favor vertical integration, assum-

89. W. S. White, Jr., and Gregory S. Vassell, "U.S. Electric Power Supply at the Crossroads-The Technical and Historical Background," Public Utilities Fortnightly, vol. 123 (January 5, 1989), pp. 9-14; and "U.S. Electricity Supply at the Crossroads-The Federal Energy Regulatory Commission Proposals,' Public Utilities Fortnightly, vol. 123 (January 13, 1989), pp. 9-13. 
ing that the integrated firms minimize costs. Are significant benefits to vertical integration likely to be forgone by relying extensively on independent generating plants linked to partially integrated utilities with long-term contracts?

There is no way of answering this question empirically with any degree of precision. Extensive vertical and horizontal integration in electricity supply is the norm everywhere on earth. If distributors are not integrated they tend to rely on long-term contracts for the bulk of their needs. Aside from the recent experience with PURPA, the world has not run a natural experiment that would make a definitive conventional empirical test feasible. And while contractual and reliability problems have not yet emerged as a serious problem with QFs in the United States, the relatively small amount of QF capacity, its recent vintage, and the lack of economic shocks that may lead to contractual failures provide too little experience to say anything definitive.

That we cannot prove which organizational mode dominates does not imply that change should be discouraged until the requisite proof and ideal changes in public policy can be achieved. The traditional system has been less than perfect, and the limited experience with independent suppliers, when a suitable regulatory environment is established, has yielded promising results. It appears feasible to proceed with changes that increase opportunities for third party suppliers to enter the market without making a definitive decision one way or the other about the relative economies of vertical or horizontal integration and contractual integration if the right regulatory environment is created. None of the participants in the public policy debate appears to be suggesting that we should require integrated utilities to divest their existing generation and distribution assets, as is being required for the monopoly generation and transmission entity (the CEGB) in the United Kingdom, or preclude distribution utilities from owning new generating capacity. ${ }^{90}$ Most pro-

90. Forced deintegration of vertically integrated utilities is in principle a possibility, but not a realistic one. Among other constraints, state regulators oppose vertical restructuring because they believe that they would lose regulatory jurisdiction over generation costs, which would be wholesale transactions subject to FERC jurisdiction. While this reflects primarily a bureaucratic battle between state and federal regulators, it is a very real constraint indeed. There was also only one AT\&T; there are more than one hundred IOUs. Any general reorganization would require federal legislation and would have to deal with financial, ratemaking, and regulatory complexities. Structural change in this industry is most likely to take place on the margin. 
ponents of these changes are talking about creating opportunities for gradual change in the extent of vertical and horizontal integration by creating incentives for independent suppliers to enter and distribution utilities to buy when it is efficient to do so. Even if some mistakes are made on the margin, they need not be fatal and are potentially reversible.

\section{Competitiveness of Wholesale Markets}

Another issue is how much price regulation of wholesale transactions is necessary. Interventionists argue that wholesale markets are not sufficiently competitive to allow prices to be determined by competitive bidding or negotiation. Noninterventionists like me argue that price regulation leads to costly distortions in wholesale trade and that reliance on even an imperfectly competitive wholesale market will lead to more efficient outcomes.

I am optimistic that the new wholesale markets are and will be competitive. The experience since the enactment of PURPA indicates that there exists a very elastic supply of capacity that independent producers are willing to offer at attractive prices. In addition, active markets for short- and medium-term power in excess of the current needs of integrated utilities have emerged in most areas of the country. Coordination and wheeling transactions have increased substantially (see table 1). These markets are subject to only very loose FERC regulation. As a result of extensive interconnections, coordination agreements and power-pooling arrangements, and voluntary wheeling, the anecdotal evidence suggests that these markets are often very competitive.

Additional evidence can be found in a 1983 experiment in which FERC encouraged a group of utilities in the West to participate in a demonstration program that provided considerable price flexibility for certain types of short-term transactions. The relaxation of formal regulatory constraints had little obvious effect-either positive or negativeon prices or quantities. ${ }^{91}$ This result is consistent with my own perception that FERC regulation of the prices for coordination transactions has not

91. Jan Paul Acton and Stanley M. Besen, Regulation, Efficiency, and Competition in the Exchange of Electricity: First Year Results from the FERC Bulk Power Market Experiment, R-3301-DOE (Santa Monica, Calif.: Rand Corp., October 1985). 
been a binding constraint in short- and medium-term coordination markets.

\section{Transmission Access and Pricing}

The extent of competition in wholesale markets is necessarily related to the number and size distribution of actual and potential competing suppliers of generation service that a distribution utility can choose from. Since potential suppliers may be remote from the areas where a distribution utility owns transmission facilities, the competitive characteristics of the market will be affected by access to and the pricing of transmission service, or wheeling. As things stand now, FERC can regulate the rates charged for transmission service, but utilities have only a very limited legal obligation under the Federal Power Act to provide it. Nevertheless, utilities voluntarily negotiate transmission arrangements with other utilities all the time. Extensive wheeling service has been made available in New England to provide contract paths for the QF power. The preliminary results of a second FERC-approved experiment allowing for the flexible pricing of transmission service in the West suggests that FERC regulation of transmission service inhibits rather than promotes wholesale trade, since relaxed regulation appears to lead to increased trade rather than reduced trade. ${ }^{92}$

Transmission access and pricing raises difficult technical, regulatory, organizational, jurisdictional, and economic problems, and is perhaps the most complex and certainly the most controversial aspect of the changes leading to increased reliance on competitive wholesale power markets. ${ }^{93} \mathrm{~A}$ comprehensive discussion of these issues is well beyond the scope of this paper, but let me make a few observations.

Most of the controversy over transmission access and pricing has been associated with wholesale requirements customers or the distri-

92. Federal Energy Regulatory Commission, Order Accepting Experimental Rates for Filing, Docket no. ER87-97-000 (March 12, 1987); "Participants Claiming Satisfaction with WSPP Bulk-Power Experiment,'” Electric Utility Week, October 24, 1988, p. 14; and Thomas W. Keelin and others, Western Systems Power Pool Assessment, Interim Report (Menlo Park, Calif.: Strategic Decisions Group, January 1989).

93. Joe D. Pace, "Wheeling and the Obligation to Serve," Energy Law Journal, vol. 8, no. 2 (1987), pp. 265-302; and Rodney Frame and Joe D. Pace, "Approaching the Transmission Access Debate Rationally," TRG Working Paper 1 (Washington: National Economic Research Associates, November 1987). 
bution of economic rents when transmission capacity is scarce relative to the demand for bulk power transactions. The disputes with wholesale requirements customers reflect more the problems associated with the terms and conditions of FERC-regulated wholesale requirements power contracts and the asymmetric obligations associated with wholesale requirements service than with the pricing or access to transmission service per se. Creative solutions to such problems have recently been approved by FERC and could serve as a model for future relationships between utilities and captive wholesale requirements customers. ${ }^{94}$ Once disputes between integrated utilities and wholesale requirements customers are resolved, issues associated with wheeling could be solved relatively easily if FERC would allow for appropriate pricing and contracting of transmission service. Reforms in FERC's transmission pricing regulations are clearly needed, as are new state and federal policies to resolve transmission line siting and certification roadblocks.

While more coherent public policies governing wholesale transmission pricing, service obligations, and siting will have to evolve, solving these problems in the abstract before continuing with the evolution of competitive pricing for wholesale power is unnecessary. The evidence from the growth and changes in the coordination market and the results of competitive bidding programs suggest that there is lots of competition to supply utilities and that wheeling service is often provided through negotiation without any special regulatory obligation. In light of the controversies over transmission access obligations, trying to create competitive wholesale markets by mandating major changes in transmission access policies is a prescription for making no progress at all. The most important regulatory reform is to remove impediments affecting entry, pricing, and procurement of generation. Once these are gone, the remaining transmission access and pricing problems can be addressed. This is the approach FERC and Congress are taking so far.

\section{Other Regulatory Barriers}

The incentives a utility has to negotiate good contracts with third parties or to seek to build generating capacity itself are largely functions of how it believes these decisions will be treated in the regulatory process

94. Pacific Gas and Electric Company, 44 FERC 61,010 (1988); and Turlock Irrigation District, 43 FERC 61,403 (1988). 
that determines how the associated costs will be treated in setting the level of retail rates. Simply requiring utilities to buy from third parties does not solve the problem. Currently the costs of purchased power contracts are dollar-for-dollar pass-throughs to rates; there are few direct incentives to pick the best mix of contracts, aside from the threat of regulatory review and the potential for cost disallowances. Furthermore, to mandate that integrated utilities must purchase all future generating needs from third parties is not likely to be efficient from the standpoint of either cost or reliability. The utility may itself be the least-cost supplier. Similarly, requiring utilities to compare third party supply opportunities with building their own capacity and subjecting utility construction to the kind of cost-of-service regulation imposed in the past decade places a significant burden on imperfectly informed regulators to guard against biases toward or against ownership of generation by distribution utilities.

If the kind of flexible competitive negotiation procedures for selecting new generating capacity that I favor are to work well, some changes in retail rate regulation are going to be required. In particular, regulations must provide utilities with better incentives to make economical supply choices independent of ownership arrangements per se. Two recently suggested alternatives to cost-of-service treatment of new utility-owned facilities point to the kinds of changes likely to be desirable. The Massachusetts Commission has announced that it has abandoned traditional rate-base cost-of-service regulation for new utility-owned generating facilities. The commission indicated that it wants to continue to give utilities the option of meeting some or all of their future needs with utility-owned generating capacity if that is the most economical choice. ${ }^{95}$ However, because it also wants to avoid what it perceives as the efficiency distortions of traditional cost-of-service regulation, the commission has proposed to replace it by negotiating a project-specific, preapproved regulatory contract with a utility, specifying the compensation arrangements that will be associated with a particular new plant in advance of construction. The regulatory contract will define ex ante

95. Massachusetts Department of Public Utilities, D.P.U. 86-36-C (May 12, 1988). The California Commission recently entered into a nontraditional "regulatory contract" with Pacific Gas \& Electric governing the pricing of power produced by the completed Diablo Canyon nuclear plant. National Association of Regulatory Utility Commissioners Bulletin, no. 2-1989 (January 9, 1989), pp. 3-6. 
exactly how utility compensation for power produced by the facility will be determined. The utility must convince the commission that the generating project is likely to be more economical than other alternatives and must agree to an incentive contract that has risk-allocation attributes similar to those being signed with third party suppliers in the region. In particular, utilities would be expected to bear construction cost and reliability risks in return for a compensation formula that yields a suitable expected rate of return on investment. Such a contract would thus partially decouple the revenues a utility receives from the costs it actually incurs. ${ }^{96}$

A task force appointed by the governor of New Jersey has suggested an alternative approach. ${ }^{97}$ Rather than getting into the details of supply procurement or writing new regulatory contracts for each new utilityowned power plant, this plan would generally decouple compensation for new generating supplies from the actual costs a utility incurs for these supplies by tying compensation to a representative index of the cost of wholesale power opportunities in the region.

The details of neither plan have been worked out, and numerous practical issues must be addressed. Both require an active wholesale market in the region that can be used to provide appropriate benchmarks either for writing regulatory contracts or for developing an appropriate index of wholesale power costs. While the Massachusetts scheme, as proposed, can work without a fully developed competitive wholesale market, I do not believe the New Jersey approach can. ${ }^{98}$ Still, the difficulties associated with trying to write an ideal regulatory contract

96. Subsequent to this order, the commission proposed a new "all source competitive solicitation" regulatory framework; Massachusetts Department of Public Utilities, D.P.U. 86-36-F (November 30, 1988). This proposal would require utilities to develop a highly structured, self-scoring competitive bidding system to solicit bids from all types of supply and conservation resources; the system would be integrated with a complex "least-cost planning process." All this would be subject to extensive and time-consuming regulatory review. The proposed rules seem extremely ill-advised. They are an unfortunate example of a few good ideas aggregated with bad administrative procedures, with the latter dominating.

97. Report to the Governor: Findings and Recommendation of the Task Force on Market Based Pricing of Elecricity, November 1987.

98. The New Jersey Task Force proposal does not appear to be going anywhere. The New Jersey Commission did recently enter into a settlement agreement that requires utilities to introduce a competitive bidding system for new generating capacity, but unfortunately the state chose to rely on a highly structured, self-scoring bidding system. 
are formidable. But both approaches recognize that the potential benefits of competitive wholesale power markets are most likely to be fully realized if changes are made so that a utility's financial performance is at least partially decoupled from its actual accounting costs. ${ }^{99}$ More effort must go into finding practical alternatives to ensure that the incentives provided by rate regulation encourage utilities to make efficient supply decisions.

There currently exist several other regulatory barriers to encouraging further development of competitive wholesale generation markets. First, some states that rely on administrative determination of avoided costs and standard-offer contracts estimate the costs incorrectly and specify terms and conditions of obligations to purchase from QFs that yield prices that are either too high or too low. Second, although several states and utilities have implemented competitive bidding and negotiation programs that seem successful, some uncertainty remains as to whether these systems are legal under PURPA.

FERC is in the process of trying to clarify its avoided-cost rules and the criteria that bidding systems must meet to be legal. In March 1988 the commission issued two notices of proposed rulemaking to achieve this objective. Unfortunately, these NOPRs, in conjunction with a related NOPR issued at the same time that proposed changes in the regulation of non-QF independent power producers under the FPA, have generated so much controversy among state regulators, legislators, and utilities that it is unclear what will happen to them. ${ }^{100}$ Fixing inefficient

99. Jean-Jacques Laffont and Jean Tirole, "Using Cost Observations to Regulate Firms," Journal of Political Economy, vol. 94 (June 1986), p. 614; and Joskow and Schmalensee, "Incentive Regulation."

100. Federal Energy Regulatory Commission, Notice of Proposed Rulemaking Re Regulations Governing Bidding Programs, Docket no. RM88-5-000 (March 16, 1988); Federal Energy Regulatory Commission, Rules Governing Administrative Determination of Avoided Costs; and Federal Energy Regulatory Commission, Regulations Governing Independent Power Producers. For the controversy, see Cheryl Romo, "1988: The Year the FERC Shook Electricity," Public Utilities Fortnightly, vol. 122 (September 1, 1988), pp. 29-32; "NARUC Electricity Panel Seeks Congressional Hearings on NOPRs"' and "Future of FERC Electricity Strategy Uncertain," Electric Utility Week, September 26, 1988, p. 15; "NARUC Representative Provides Views on FERC Electricity Policy Initiative to Congress," National Association of Regulatory Utility Commissioners Bulletin, no. 38-1988 (September 19, 1988), pp. 15-18; and "Senators Urge FERC Not to 'Rush to Judgment' on Electricity NOPRs,' Electric Utility Week, September 26, 1988, p. 14. 
price regulations and allowing for competitive bidding and negotiation is essential if this experiment with unintegrated third party suppliers is to yield efficient outcomes.

For those of us interested in expanding the utilities' opportunities and incentives to choose among the widest array of generation options (including vertical integration), the reforms proposed in a third FERC NOPR dealing with independent producers seem especially important. Ideally, a utility should be able to turn to the most economical supply sources, whether QF generating plants, independent non-QF plants, excess capacity and energy available from proximate utilities, or internal utility production. Substantial QF capacity has been forthcoming primarily for two reasons: utilities have an obligation to buy at (in theory) a competitive price and QF suppliers have been freed from cost-ofservice regulations. QF suppliers have been able to take on construction cost and reliability risks because compensation is not tied to their accounting cost of service or to prudence reviews. A wholesale supplier that is not a QF under PURPA, however, is subject to rate regulation under the Federal Power Act rather than PURPA. The rates charged for long-term wholesale power supply contracts from single facility wholesale suppliers subject to FPA jurisdiction have traditionally been regulated by FERC using traditional embedded cost-of-service accounting principles, even though the FPA does not appear to mandate this.

Without changes in the way rates and related contractual provisions for non-QF independent wholesale suppliers are regulated, a viable, efficient, and competitive wholesale power market that includes nonutility generators simply will not emerge because traditional regulation does not provide adequate incentives for an independent supplier to incur the risks associated with competition. Given uncertainty about production costs, plant performance, and changing market conditions, a system that allows an independent supplier to recover nothing more than its accounting cost of service at any point in time, as traditionally defined by regulators, means that a supplier can only expect to recover costs by entering into a life-of-plant, accounting-cost-of-service contract with a distribution utility before it enters the market. To see this, assume that the typical independent supplier expects to be able to supply electricity for 5 cents per $\mathrm{kWh}$, but because of uncertainty the cost could turn out to be 4 cents or 6 cents. The supplier considers entering the market and selling output under a series of short-term contracts with a 
maximum price equal to the accounting cost of service at each point in time. While the supplier is free to sell for a price up to whatever its actual accounting cost of service is at any time, the distribution utility buyers are not under any obligation to buy at that price in the absence of a previous commitment. When the seller realizes a 4 cent cost of service, there will be many interested buyers. When it realizes a 6 cent cost of service, buyers are likely to turn to less costly alternatives, and the seller will have to charge less than the accounting cost of service. By setting an accounting cost-of-service ceiling on prices, the potential entrant faces the unappealing prospect of being compensated for its realized accounting costs or the current market value of his capacity, whichever is less. The potential entrant might be satisifed with a contract that simply agreed to pay 5.5 cents per $\mathrm{kWh}$. This would yield an expected profit of 0.5 cents per $\mathrm{kWh}$. However, such a contract would violate the accounting cost-of-service ceiling whenever the supplier's accounting costs are below 5.5 cents.

If the United States wants to encourage competitive entry of non-QF suppliers into generation and meaningful competition to supply unintegrated or partially integrated utilities, reforms in federal regulation under the FPA of the contracts negotiated with these utilities are necessary. In particular, the suppliers will have to be treated in much the same way as QFs are under PURPA. They must be exempted from cost-of-service regulation in much the same way as nondominant long-distance telephone companies have been exempted from it by the Federal Communications Commission.

FERC's notice of proposed rulemaking for independent power producers goes a long way toward removing FPA restrictions on entry and contracting between independent power suppliers and distribution utilities. The IPPs would constitute a new class of suppliers that will not be subject to cost-of-service regulation. Since the FPA may not give FERC the formal authority to deregulate the terms and conditions of contracts negotiated by IPPs, the regulatory changes have been described as providing "relaxed regulatory treatment." Basically, the proposed treatment provides that contracts negotiated by IPPs that do not have significant market power would be presumed to be just and reasonable and would not be subject to cost-of-service regulation. To guard against monopoly pricing and self-dealing, the notice proposes the criteria an IPP must meet to receive such treatment. Among other things, the rates 
in the contracts (properly discounted) must have an expected value less than or equal to the buying utility's avoided costs (properly discounted), the seller cannot have dominant control over the buyer's access to competing suppliers, and the transaction must be between unaffiliated entities (to avoid self-dealing between a regulated distribution company and a wholesale affiliate).

While I do not agree with all of the details of the IPP proposal, its basic intent makes sense. It does not force utilities to buy from independent producers, but it creates a regulatory environment that allows them to do so. In particular, it provides symmetry between QFs and non-QF independent suppliers and allows utilities to integrate $\mathrm{QF}$ and non-QF sources in a common competitive procurement process. Although the prospects for the IPP proposal are uncertain, FERC can accomplish the same results through case-by-case consideration of applications by IPPs for the kind of regulatory treatment proposed in the IPP notice. ${ }^{101}$

\section{Conclusions}

The firm and industry structure and regulatory arrangements that governed the electric power industry for three decades following World War II were poorly adapted to dealing with the economic turmoil that developed after 1973 . While it may be that no regulatory system would have worked smoothly under such conditions, the economic shocks mobilized interest groups to seek alternative institutional arrangements in response to them. The regulatory process and legislative oversight of it became forums through which these groups could extract economic rents. The long-run effects have been to raise serious questions about the viability of the traditional arrangements, which have led to efforts to reform the regulatory process to improve incentives for efficient performance. Some of these reforms can help; others, such as "prudence" disallowances, merely reflect changes in the rules made possible by

101. The Public Utility Holding Company Act of 1935 creates another federal regulatory barrier. See Statement of Catherine C. Cook (with attachments), Federal Energy Regulatory Commission, and Statement of Marianne Smythe (with attachments), Securities and Exchange Commission, before the Subcommittee on Energy and Power of the House Committee on Energy and Commerce, September 14, 1988. 
poorly defined legal principles and opportunities to reallocate rents associated with changing economic conditions. The latter unfortunately have adverse consequences for utility investment and operating behavior in the future.

This turmoil has also precipitated interest in providing incentives to distribution utilities to secure the most economical supplies of generating capacity and in expanding opportunities for independent suppliers to compete in the market. The experience under the Public Utility Regulatory Policy Act of 1978, though not without its problems, has provided evidence that independent suppliers can serve at least some of a utility's generation needs economically and without compromising system reliability. The experience has helped significantly to promote interest in developing an independent generation market.

This recent experience with small independent generators qualifying under PURPA does not of course prove definitively that the traditional institution of regulated integrated monopoly electricity supply is dominated by organized changes that would transform it into an industry made up of numerous competing generating companies selling power to unaffiliated regulated distribution and transmission companies. Even if it had not been vertically integrated, just as the natural gas industry is not vertically integrated, the economic turmoil of the 1970s and 1980s would have almost certainly created enormous stresses on an industry whose primary pieces were linked together by long-term contracts. Vertical separation has not, for example, saved the natural gas industry from chaos associated with unanticipated changes in economic conditions after 1984. Furthermore, experience with independent suppliers is still limited and, when bad regulatory procedures have been applied, quite poor.

The independent generator cat is now out of the bag, however, and I see little reason to try to stuff it back in. In states that have allowed utilities to adopt sensible competitive bidding and negotiation systems for nonutility generators, the results have been promising. Now that independent suppliers have become a significant presence, they will inevitably bring pressure to open up more opportunities and to create a regulatory environment for distribution utilities that can accommodate them effectively. There are, however, many legitimate questions about how reliably and economically the system will perform if it comes to rely exclusively on competing independent suppliers. Perhaps the feared 
problems will not emerge, or perhaps they will be no more costly than the imperfections of the traditional arrangements. The primary task for state and federal regulatory agencies is to develop a regulatory environment sensitive to both the opportunities and potential problems that the movement to a deintegrated system based on competing independent suppliers of generation capacity raises. Several state commissions, the Federal Energy Regulatory Commission, and a number of utilities have made significant progress along these lines. There is still a lot to do to create a more effective regulatory environment to accommodate efficient change, and plenty of room to learn quickly from the inevitable mistakes. 


\section{Comments \\ and Discussion}

Douglas R. Bohi: Paul.Joskow's paper on the structural and regulatory changes under way in the electric power industry fills a gap in the scholarly literature on the wholesale electric market and answers some of the questions raised by recent actions of the Federal Energy Regulatory Commission (FERC) to increase competitive entry into the electric generation sector. Joskow observes that the literature has not anticipated the kinds of changes being proposed. He emphasizes the evolution of the industry toward greater competition, culminating with FERC's proposals to introduce competitive bidding for new generation capacity and reduce regulation of so-called independent power producers. This approach gives the reader a good idea of the pressures building on the commission to reduce regulatory barriers. Alternatively, the author could have organized the paper to emphasize the benefits and costs of imperfect competition and imperfect regulation.

Joskow demonstrates that long before FERC's proposals the electricity market was becoming more competitive because of growing disillusionment with traditional regulation and the response by buyers and sellers to changes in incentives. Consequently, many of the same issues concerning the benefits of competition would have to be addressed whether or not the commission acted. There is then the additional question of whether the commission's actions would help or harm the situation.

The view that something must be done about the current system of regulation follows from a basic tension between the ideal of competition and the two tenets of traditional regulation-cost-based pricing and the obligation of the industry to serve. Joskow does not highlight this tension-his focus is on competition among suppliers of generation services in wholesale markets rather than competition for customers in 
retail markets-but the problem is present nevertheless. The municipal wholesale requirements customer is the analogue to the industrial customer shopping around in retail markets. In both cases a problem of stranded investment arises, comparisons of regulated rates need not signal the efficient use of resources, and lack of access to transmission is a barrier to competition.

A critical element in the case for more competition in generation services is the presence of natural monopoly conditions. Although Joskow does a nice job of explaining complexities of determining economies of scale and scope as well as the benefits to vertical integration from coordination and system reliability, it is not possible to get a sense of the magnitude of these benefits and how they may have changed with the introduction of new technologies for generation and the expansion of the grid system. Nevertheless, I would like to have Joskow's views on a number of questions that have not been addressed. Why are there so many utilities if the gains from mergers are potentially so large? What is the record of success or failure with power pools? What does the increased coordination trade among members of the Western Systems Power Pool suggest about the advantages from less regulation? Are there serious free-rider problems with decentralized generation supply? Are there lessons to be learned from experience in the electric industry, or from experience with other industries, about the potential problems of depending on contracts for generation services?

The experience under PURPA has been critical to the argument for competition in generation supply, in part because the successes with new and smaller-scale technologies further diluted the natural-monopoly argument for regulatory barriers to entry. In addition to the points Joskow lists about the effect of the 1978 act, I would add that FERC could not have realistically entertained the proposed rules on competitive bidding and independent power producers without the experience with partial deregulation provided by PURPA. Not only was the response by independent generators much more elastic than anyone imagined, but this experience also demonstrated that adequate financing was available to independents, that they could actually build plants on time and on budget, that they could operate them as reliably as utilities could theirs, and that, in short, utilities' obligation to serve need not be equated with an obligation to build.

A key argument against competitive entry into generation supply is 
that decentralized supply sources may pose problems in reliable service and coordination. As Joskow notes, these problems have not yet emerged in connection with QFs and other independent suppliers; but their share of total capacity is small and their participation recent. Still, I agree with the author: the lack of empirical evidence about the relative desirability of alternative industry structures does not imply that change should be discouraged until the requisite proof can be established. The opponents of change, of course, take the opposite view and buttress their argument by pointing to mistakes in implementing PURPA as examples of problems that will be encountered with decentralized supply of generation services. However, mistakes in pricing QF power and ignoring dispatchability or other reliability factors have long since been corrected. Just as more attention is now paid to getting the price right, so more is paid to the various kinds of power being priced.

Another component in the debate is the growing realization that regulatory institutions may not be very effective in protecting the public's interest. This concern arises even in cases in which public utility commissions are zealously questioning the prudence of utilities' decisions or setting avoided costs to encourage the entry of QFs. These problems arise because the regulations are impossible to implement effectively and because state commissions seldom have the analytical capability required to carry out their responsibilities. In the latter connection, Joskow's references to fairly sophisticated initiatives undertaken by the Massachusetts Department of Public Utilities-overseeing negotiations on complex nonprice factors in the bidding process or negotiating new "regulatory contracts" with utilities that exchange flexible incentives for risk-allocation provisions-cannot realistically serve as models for most other states.

The perceived need for giving the states more guidance explains in part the tendency for excessive discussion in FERC's proposed rules on competitive bidding, for which the commission has been criticized as creating more controversy than necessary. Another reason is that the discussion attempted to respond to comments received by the commission through public conferences during the spring of 1987 and comments received on a 1985 notice of inquiry. For some issues, such as the perceived problem of multiple avoided costs established for the same utility operating in more than one state, FERC simply misjudged the 
extent of concern expressed and set about correcting a problem that not even the utilities involved thought was important.

Joskow omits one highly controversial issue that arises in connection with competitive bidding for new capacity: whether to require some form of transmission access for QFs and other independent generators that participate in a bidding program. If benefits are to result from easing entry barriers to new generation, it must be recognized that a major barrier is the lack of transmission access. Moreover, the lack of access generally limits the independent generator to transactions with a single buyer, and the independent's expectation that its investment would be held hostage severely limits the flexibility of the contract relationship. However, transmission access is a big topic, even in the narrower context of conditions imposed on bidding programs, and the subject for another paper.

Frank M. Gollop: Paul Joskow's paper is a neat primer on the evolution of modern regulatory policy in the industry, with a special focus on the regulatory consequences of the economic shocks of the 1970s. To stop with this observation, however, would miss the paper's main point. Joskow singles out the blossoming competition in wholesale electricity markets and develops an argument for how competition in generation may be stimulated and broadened to address some of the distortions created by regulation.

The interesting part of the story begins in 1978, the year Congress passed the Public Utility Regulatory Policy Act (PURPA). As Joskow comments, Title II obliges integrated utilities to purchase power from and provide backup supplies to both companies that engage in cogeneration regardless of size and small companies that produce power using renewable energy sources. These qualifying facilities (QFs) have a guaranteed market for their power at prices equal to the avoided cost of the purchasing utilities. More important, they are not utilities under the Federal Power Act and are therefore exempt from rate-of-return regulation. Not surprisingly, PURPA has reversed what had been a downward trend in the absolute and relative importance of stand-alone generation companies.

Joskow proposes a number of reforms that, by increasing competition among independent power producers, should reduce important distor- 
tions arising under the PURPA-mandated regime. Among these are recommendations that the definition of qualifying facilities be broadened to include independent power producers and that administered avoidedcost and standard-offer contracts be replaced by competitive bidding and, especially, negotiated contracts. The recommendation of most interest is that integrated utilities not be compelled to purchase power from qualifying facilities. A utility should be allowed to meet its capacity needs through additional self-generation, but if and only if it can demonstrate to its commission's satisfaction that self-generation would be less costly than purchasing power. Herein, as Joskow recognizes, lies the problem.

Consider the incentives facing an integrated utility choosing whether to supply its own power or purchase it. On the one hand, Joskow argues that "because expenses for purchased power are more or less passed through automatically in retail rates, the regulatory process historically provided little profit incentive to rely on purchases from third parties to meet capacity needs." On the other hand, utilities have rightfully come to believe that regulators have broken the regulatory contract. Disallowances because of imprudent behavior have been used to resist large rate increases even if those increases are fully justified by cost increases. Decisions are tilted in favor of external purchases. The biases push in opposite directions. It is unclear which one dominates. What is clear is that each is the result of rate-of-return regulation, whether applied or misapplied, and the unequal treatment of stand-alone generating companies and utilities owning generating capacity. Thus utilities make decisions based on regulatory rather than economic signals, and the resulting inefficiencies lead to higher retail rates than necessary and a corresponding reduction in social surplus.

The critical task is to devise a regulatory scheme that induces utilities to behave in a regulation-neutral, cost-minimizing way. Clearly, the PURPA requirement that utilities meet their capacity needs by purchasing from qualifying facilities is not the answer. If I have any disappointment with the paper, it is that it does not provide a satisfactory answer to this problem.

Joskow points to changes in retail rate regulation suggested in Massachusetts and New Jersey as examples of potentially desirable plans. Both proposals maintain rate-of-return regulation on existing plants but offer separate contract schemes to determine the utility's compensation 
on new generating plants. The Massachusetts Commission proposes a regulatory contract that promises a reasonable return on new investment. The New Jersey proposal (no longer being actively considered) would have required compensation for self-generated or purchased power to be tied to comparable wholesale power costs in the region. The Massachusetts proposal is in effect a rate-of-return regulation. The only difference is that the commission promises, this time, to abide by the contract. The New Jersey plan would require a fully competitive wholesale market (which does not yet exist) and would promise ratepayers final prices reflecting nothing better than the efficiency of the average wholesale supplier in the region.

The proposals suffer from even more fundamental problems. First, why the unequal treatment of existing and new plants? The political rationale can be inferred. The economic justification cannot. Second, the difficulties, as Joskow recognizes, with writing ideal regulatory contracts are considerable. Third, the low-cost producer in the Massachusetts instance and the competitive price for wholesale power in the case of New Jersey will be determined in the hearing room not in the open marketplace. In that forum no agent has any incentive to reveal the known or expected truth about its production costs or wholesale market conditions. Ultimate production and purchasing decisions will be made with respect to regulatory outcomes, not market forces.

The need for reform is still there. But without eliminating the present distortions, adopting Joskow's (and PURPA's 1988) recommendation to broaden the definition of qualifying facilities may only exacerbate the problem. Joskow fails, then, to go far enough. He does not offer a policy prescription (however tentatively stated) that would induce utilities to seek least-cost power. In the interest of stimulating discussion, let me suggest two options, either of which would lead utilities to engage in regulatory neutral behavior: price-cap regulation and the divestiture of generating operations from integrated utilities.

A properly designed price cap would induce the fully integrated utility to behave as a true cost minimizer. Indeed, it can be demonstrated that the price-cap formula is derived directly from the factor-minimal cost function. The allowed maximum rate of change in retail rates would equal the expected rate of change in input prices less some incentivepreserving share of the difference between actual and expected total factor productivity growth. Unlike rate-of-return regulation, price-cap 
regulation treats all inputs as equal. The firm is truly indifferent between self-generated power and purchased power. Its myopic objective is to minimize costs. (To protect against excessive profits, the regulators may apply a progressive share parameter to the formula's productivity component.)

Divestiture would retain rate-of-return regulation on transmission and distribution but would allow generation to be competitive. The traditional rationale for a natural monopoly applies unarguably only to distribution, perhaps to transmission, and, most would agree, not at all to generation. Joskow argues for the continued vertical integration of generation, transmission, and distribution because linking investments in and operations of decentralized generation and transmission systems efficiently through bilateral contracts may entail significant costs. That, however, argues for coordination and planning, not vertical integration. The linkages are engineering not organizational. Moreover, power pools and wheeling arrangements respond to Joskow's concerns without requiring integration. Successful decoupling not only would further stimulate competition among power suppliers but would also eliminate the current regulation-induced resource misallocation between selfgenerated and purchased power.

Each option has its own peculiar implementation problems and each is certainly more far reaching than the Massachusetts or New Jersey strategies, but each has the merit of addressing and eliminating the decision-distorting incentives endemic to current regulatory practices. Each permits the regulated utility to select the lowest-cost producer. Either leads to an increase in social welfare. The demonstrated effectiveness of power pools and wheeling arrangements prevents the eruption of monopoly or monopsony power under either option. Political realities and our experience in telecommunications, however, suggest that a transition to price-cap regulation would attract less opposition than divestiture.

In any case, the competitive genie has escaped its bottle. If we have learned anything from our collective research into regulated sectors in general and telecommunications in particular, it is that a marketplace containing some regulated and some unregulated "competitors" is a marketplace in disequilibrium. Firms quickly learn how to circumvent regulatory policies that fail to mirror market forces. 
The time is ripe for regulatory change. Disallowances of compensatory costs of utilities have broken the rate-of-return contract. Integrated utilities want to be freed from the PURPA requirement compelling them to buy power from qualifying facilities. Nonqualifying independent producers want their status changed. Regulators truly desire an efficient solution but do not want to abdicate their authority. Clearly, it is to the advantage of all parties to implement the rules for competition among generating companies well in advance of the not-too-distant day when superconductivity enlarges the geographic area of effective competition.

\section{General Discussion}

Participants were concerned that the paper had not gone far enough toward proposing reforms that would address the tension between, as Douglas Bohi phrased it, "imperfect regulation and imperfect competition." Roger Noll asked why the distinction between price caps and rate-of-return regulation would matter if the regulatory regime insisted on competitive bidding for generation facilities and separate generation subsidiaries within the investor-owned utilities. Joskow agreed that this distinction was not important per se, but said the central regulatory problem was how to create some sort of incentive for utility companies to work hard at finding the cheapest possible source of power. The most difficult, and important, part of the problem for regulators, Joskow added, is to come up with a pricing scheme that provides the right incentives, yet avoids the problems associated with monopoly in the retail end of the utility business. With the right pricing scheme for power and transmission services, other issues, such as encouraging utilities to wheel wholesale power back and forth to exploit all possible efficiencies, would tend to take care of themselves.

Competitive bidding for power is an attractive solution and might be the best long-run solution, several participants seemed to agree. Joskow pointed out that some utilities are very good at building and operating generating plants and would thrive under a competitive bidding regime, whereas others would not be able to compete in that market. Competitive bidding would thus serve to weed out the good ones from the bad ones, which has clear efficiency benefits. For this reason especially, Robert 
Willig observed, it would be very inefficient to exclude the integrated utility itself from playing in the auction. But, Richard Gilbert pointed out, as a regulated generator, the investor-owned utility is in a risky position under current regulation and current pricing policies because it gets paid last. This creates a bias against own-generation (which works against the historical bias in favor of own-generation resulting from rateof-return pricing) in the decisionmaking process for the utilities. Finally, Joskow noted that vertical disintegration would be difficult politically and likely to draw opposition from the "hundreds of utilities out there" and the regulatory commissions in fifty states.

Willig favored price caps on generated power, with continued rateof-return pricing on transmission and distribution, as a solution that could be implemented more quickly. The price cap solution creates incentives for utilities to source power efficiently, but it presents difficult problems in determining the right price index to use to set the caps. Joskow observed that as the wholesale market develops, the price signals from this market could be used to set caps, but in the meantime caps would have to be set in a much less economically satisfactory way, such as tying the caps to movements in fuel prices or in the CPI. As a transitional device while the wholesale market has time to develop, Willig noted, the New Jersey commission staff suggested the "QF settlement," a formula that the QF (qualifying facilities) industry, the utilities, and the regulators developed to meet the PURPA avoided-cost standard. 